\title{
RESEARCH / INVESTIGACIÓN \\ Análisis de los atractivos turísticos de una ciudad intermedia: El caso de Bahía Blanca, Argentina
}

\section{Analysis of the tourist attractions in an intermediate city: The case of Bahía Blanca, Argentina}

Daniella Melisa Gambarotaํㅗㄹ María Amalia Lorda².

Resumen: Actualmente el turismo es una actividad reconocida como motor de desarrollo en un territorio, provocando que los gobiernos y entidades privadas le otorguen una mayor atención a través de la promoción de diferentes programas y actividades relacionados con el turismo. Durante las últimas décadas se observa un proceso de desvalorización de productos y áreas tradicionales y, simultáneamente, se crean y valorizan nuevos productos alternativos. La ciudad está tomando un carácter relevante por la variedad de atractivos y actividades que se ofrecen. Bahía Blanca, ciudad ubicada al sudoeste de Argentina, es un centro urbano intermedio, posee atractivos y se está posicionando en el turismo de congresos y convenciones. El objetivo de este trabajo fue analizar la situación turística actual de Bahía Blanca a fin de conocer las fortalezas y oportunidades que posee respecto al turismo. La metodología incluyó una indagación bibliográfica respecto a las ciudades intermedias y su rol en el territorio, el turismo urbano, la presentación de los principales circuitos y propuestas turísticas que se gestionan desde el Municipio de Bahía Blanca, y el análisis de los atractivos actuales de la localidad con el objeto de conocer cuáles son las fortalezas y oportunidades que posee respecto al turismo. Una importante conclusión es que las ciudades intermedias pueden desempeñar un papel importante en la organización y desarrollo de las actividades regionales y Bahía Blanca reúne condiciones para un buen desempeño, dado que tiene capacidad para atraer actividades competitivas, como lo son las turísticas.

Palabras clave: Centro urbano intermedio, turismo de congresos y convenciones, actividades competitivas.
Abstract: Tourism is an activity currently recognized as the development engine in a territory, such that governments and private organizations give it greater attention by promoting different tourism-related programs and activities. In recent decades, a devaluation process of traditional products and areas has been observed, while at the same time new alternative products are being created and developed. The city is taking on a relevant character due to the variety of attractions and activities offered. Bahía Blanca, a city in southwestern Argentina, is an intermediate urban center; it has attractions and is positioned in the tourism of conferences and conventions. The aim of this study was to analyze the present tourism situation in Bahía Blanca to learn about the strengths and opportunities it has regarding tourism. The methodology included a bibliographic search of intermediate cities and their role in the territory, urban tourism, the presentation of the main circuits and tourism proposals under the management of the Municipality of Bahía Blanca, and an analysis of its current attractions in order learn what strengths and opportunities it has regarding tourism. An important conclusion is that intermediate cities can play an important role in the organization and development of regional activities and Bahía Blanca meets the conditions for a good performance, given that it can attract competitive activities, which include tourist activities.

Key words: Intermediate urban center, conference and convention tourism, competitive activities.

\section{(Presentado: 11 de julio de 2018. Aceptado: 29 de agosto de 2018)}

\footnotetext{
1 Instituto de Investigaciones Económicas y Sociales del Sur, Consejo Nacional de Investigaciones Científicas y Técnicas. Departamento de Geografía y Turismo, Universidad Nacional del Sur, Bahía Blanca, Argentina. E-mail: danielagambarotągmail.com

${ }^{2}$ Departamento de Geografía y Turismo, Universidad Nacional del Sur, Bahía Blanca, Argentina. E-mail: mariaamalialayahoo.com.ar
} 


\section{INTRODUCCIÓN}

El turismo es una actividad que en la actualidad es reconocida como motor de desarrollo en un territorio provocando que los distintos gobiernos y entidades privadas le otorguen una mayor atención promoviendo diferentes programas y actividades de fomento a la misma. Esta actividad se ha convertido en los últimos años, en un factor fundamental de desarrollo socioeconómico de los países (Kotler, 1997), habiéndose otorgado a nivel mundial mucha importancia al desarrollo de distintas actividades relacionadas con el ocio y la recreación, buscando satisfacer las crecientes e innovadoras demandas de los turistas.

Durante las últimas décadas, profundas transformaciones se han producido debido a la irrupción de la revolución tecnológica, el proceso de globalización de la economía y de la comunicación, modificando las formas de producir, consumir, informar, gestionar y pensar. Estos cambios han influido en la actividad turística, la cual debe adaptarse a las nuevas demandas de los viajeros.

En el sistema turístico actual el 'turismo urbano' ocupa hoy un lugar destacado, tal como lo destacan diversos estudios (Judd y Fainstein 1999; Page 1995; Selby 2004). Bertoncello (2016:110) afirma que las ciudades se van transformando en destinos turísticos privilegiados ya que: "concentran una amplia gama de servicios y atractivos, de actividades posibles de ser realizadas por los turistas, de manifestaciones culturales para observar y reconocer. Desde el conocimiento de sus barrios y 'rincones' peculiares y distintivos hasta la visita a un centro comercial o el paseo por sus peatonales, todo en ellas se transforma en un apelativo para el turismo".

Bahía Blanca, por su condición de centro urbano intermedio, junto al impulso de la actividad turística que se está produciendo en las ciudades, posee una verdadera oportunidad de desarrollo. En palabras de Vera (1997:18): "...la creciente demanda de destinos y experiencias alternativas ha propiciado que todos los espacios sean potencialmente turísticos, en razón a su especificidad" y agrega (1997:12): "El turismo debe ser reconocido [...] como pieza en la construcción de nuevos espacios de crecimiento a escalas regional y local [...], en la transformación de las sociedades y territorios".
En el presente trabajo se expondrá la situación turística actual de la localidad de Bahía Blanca, analizando su posicionamiento, su calidad como ciudad intermedia y sus atractivos turísticos.

\section{METODOLOGÍA}

Metodológicamente se partirá de una indagación bibliográfica respecto a las ciudades intermedias y su rol en el territorio, el turismo urbano, se expondrán los principales circuitos y propuestas turísticas que se promueven desde el Municipio de Bahía Blanca, y a su vez se analizarán los atractivos actuales de la localidad con el objeto de conocer cuáles son las fortalezas y oportunidades que posee respecto al turismo.

\section{Una aproximación a las ciudades intermedias}

Actualmente el mundo es predominantemente urbano, las ciudades crecen a ritmo acelerado y predominan las urbes con una gran concentración de personas y de tecnología, en el extremo contrario se ubican los núcleos urbanos más pequeños y en una posición media, las ciudades intermedias las cuales están cobrando protagonismo en las últimas décadas gracias a su potencialidad. Prieto et al (2011:2), afirman que los centros urbanos intermedios son prestadores de servicios y bienes especializados, y se considera que presentan adecuadas condiciones para las iniciativas de desarrollo local.

Para identificar y denominar a las ciudades intermedias se aplican diversos criterios cuantitativos que tienen relación con las realidades de los territorios y las funciones que se le reconocen. En América Latina, según Rodríguez, (2002:38) se pueden considerar los centros urbanos de más de 50.000 habitantes y menos de 1 millón. Más importante que el tamaño demográfico, es su caracterización por sus funciones importantes como centro de servicios regional. Llop (2008:13), advierte que el concepto ciudades intermedias es transversal ya que incorpora a las dimensiones física y demográfica, "la intermediación, como dimensión intermedia o estar en medio de flujos y de espacios diversos". "La doble cuestión a destacar en el momento de la definición de la ciudad intermedia, es que la talla mediana está en función del tamaño de la población... y que siempre tienen sentido y funcionan en y para un territorio regional, concreto y característico". 
Bolay y Rabinovich (2004), incorporan la esfera cualitativa y la noción de intermediación, como rol esencial de los centros urbanos y tiende a desplazar la definición de ciudad media que considera variables demasiado rígidas, como la densidad o el tamaño demográfico (Bellet, 2004:30; Pulido, 2004), para atender aspectos relacionados con la función de dicha ciudad en contextos territoriales definidos, su radio de influencia y las redes y flujos que genera hacia su hinterland. Estas nuevas dimensiones destacan el dinamismo demográfico y funcional, junto con una mayor capacidad de integración a redes locales, nacionales e internacionales (Pulido, 2004).

El Programa ESPON (2006) menciona actividades terciarias que deberían estar presentes en las ciudades intermedias, entre las cuales se pueden mencionar: los servicios financieros y empresariales, comercio minorista, servicios sociales y administrativos, educación en diferentes niveles, prestación de servicios agrícolas y turismo y recreación. Por su parte, los autores Bellet y Llop (2004) plantean que las funciones de intermediación pasan por la concentración de actividades y servicios especializados que también reflejan las estructuras de ocupación laboral de estas ciudades.

Las ciudades intermedias según lo asevera Méndez (2006), deben actuar como intermediarios entre la gran ciudad y los espacios rurales; como proveedores de bienes y servicios especializados, así como centros de interacción social, económica y cultural para su entorno. Por otro lado Rodríguez (2004:40), plantea que las posibilidades para una ciudad intermedia están condicionadas por: a) su base económica y sus relaciones con el sistema global, b) su articulación al sistema urbano regional y nacional, y c) el aprovechamiento de ventajas comparativas en materia de producción, oferta de servicios, infraestructura, generación de conocimiento e información. Retomando a Prieto (2011), se puede considerar que en el contexto actual las ciudades intermedias parecen estar mejor posicionadas para cumplir con estas funciones ya que disponen de tecnológicas, económicas, políticas y culturales, que se refuerzan mutuamente.

La ciudad intermedia no puede definirse solo por su tamaño demográfico. Es importante el papel y la función que juega en su territorio más o menos inmediato, la influen- cia y relación que ejerce y mantiene en éste y los flujos y relaciones que genera hacia el exterior. Algunas de las características que ayudan a definir el rol de una ciudad intermedia en su territorio, en una escala local/regional, son las siguientes: centros servidores de bienes y servicios más o menos especializados para la población del municipio y de otros municipios cercanos sobre los que ejerce cierta influencia; centros de interacción social, económica y cultural; centros ligados a redes de infraestructuras que conectan las redes locales, regionales y nacionales e incluso, algunas, con fácil acceso a las internacionales (como en el caso de las ciudades medias de las periferias metropolitanas). Son nodos que articulan flujos, puntos de referencia y de acceso a otros niveles de la red; centros que suelen alojar niveles de la administración de gobierno local y regional a través de los cuales se canalizan las demandas y necesidades de amplias capas de la población.

\section{El turismo urbano}

El turismo en las ciudades tiene su inicio a partir del Grand Tour, cuando los jóvenes europeos en los siglos XVI y XVII recorrían las principales ciudades del viejo continente, con el objetivo de perfeccionarse en su vida político profesional. Según lo afirma Barreto (2009:169): "el turismo urbano contemporáneo surge en el contexto de la restructuración económica de las sociedades llamadas postindustriales, de la globalización y de su contrapartida, la búsqueda de una identidad local. [...] Recién en la última década del siglo XX aparecieron algunas publicaciones sobre el tema y se realizaron algunos seminarios internacionales con la contribución de expertos. Esto es inclusive paradójico ya que la historia del turismo, desde sus orígenes en el gran tour, se vincula al espacio urbano."

Antón Clavé (2008:56) identifica las causas por las cuales la ciudad se convierte en un atractivo de visitantes entre las que se destacan: "la generalización de la nueva cultura de consumo del tiempo libre, con la transformación de los procesos productivos, organizativos y espaciales, con la puesta en valor de los elementos clave del patrimonio, con la inserción del turismo como instrumento de crecimiento en las estrategias de la ciudad y, sobre todo, con el desarrollo de los eventos como estrategia del marketing urbano y la puesta en marcha de diferentes tipos de instalaciones recreativas, culturales y comerciales [...]". 
La OMT (Citada por Pinassi y Ercolani, 2012:2) define al turismo urbano de una manera limitada: "los viajes a las ciudades o los lugares de gran densidad de población." En cambio, Rodríguez Vaquero (2009:174), propone una definición más descriptiva y tiene en consideraciónel espacio sobre el que se desarrolla la práctica turística: "para definir el turismo urbano, de ciudad o de espacios urbanos, existen dos perspectivas diferentes: cualquier modalidad de actividad turística que se lleve a cabo dentro de un espacio catalogado como urbano y conjunto de actividades específicamente ligadas a la esencia de la ciudad más vinculadas con prácticas económicas (negocios), académico-formativas (estudios, seminarios, simposios, eventos y congresos) y sociales en general, que lleven a cabo los propios usuarios turísticos. En definitiva, es el que se realiza en la ciudad sobre el modelo de modo de vida urbano y comprende todas aquellas actividades que realizan los turistas y visitantes durante su estancia en la ciudad, ya sean culturales, recreativas o profesionales".

El turismo metropolitano entendido como una extensión del urbano tradicional, asociado al turismo cultural y patrimonial (no referente a la escala de ciudades), fue analizado por diversos autores tales como Marchena Gómez, (1995); Vera Rebollo et al., (1997 y 2011) y Rodríguez Vaquero, (2009), consideran al turismo cultural como práctica de ocio en el espacio urbano, sumado a nuevas actividades enmarcadas en el contexto dinámico, profesional, productivo y económico de las ciudades. Es en este contexto que se consolidan modalidades turísticas, vinculadas al turismo de congresos y convenciones, el turismo de negocios y las motivaciones asociadas al entretenimiento y las compras.

Determinadas características deben darse en una localidad en la que se desarrolla el turismo urbano, entre las cuales se destacan según Marchena Gómez (1995:9-10), las siguientes: la formación-capacitación propia del sector turístico para satisfacer la demanda turístico-recreativa de la ciudad y la del producto turístico en sí mismo; la mejora del ambiente urbano: puesta en valor del espacio urbano; el desarrollo de infraestructura: accesibilidad física y económica al destino; el desarrollo de una "oferta central" y complementaria: posibilita el desarrollo de propuestas diferentes y la captación de diversos públicos objetivo; y el equilibrio entre los principales actores en el destino: es necesaria una articulación entre las "áreas de negocio [...], investigación [...], burocracia administrativa [...], tecnologías [...] y zonas cuya única vocación es el ocio de los ciudadanos y los turistas: los parques temáticos y los grandes espacios públicos de calidad”. El autor señala que además es necesario desarrollar una identidad propia, basada en el patrimonio histórico y cultural de la sociedad local. De esta manera en la ciudad confluyen diversas actividades, infraestructura y atractivosculturales, profesionales y recreativos.

\section{RESULTADOS}

\section{Caracterización de la ciudad de Bahía Blanca}

Ubicada en el sudoeste de la Provincia de Buenos Airesa los $38^{\circ} 44^{\prime}$ Latitud Sur y $62^{\circ} 16^{\prime}$ Longitud Oeste sobre la costa del océano Atlántico; Bahía Blanca es la localidad cabecera del partido homónimo que incluye las localidades de Ingeniero White, General Daniel Cerri y Cabildo limitando con los distritos de Villarino, Tornquist, Coronel Pringles y Coronel Rosales, siendo su superficie de 2.300 $\mathrm{km}^{2}$ (Figura 1).

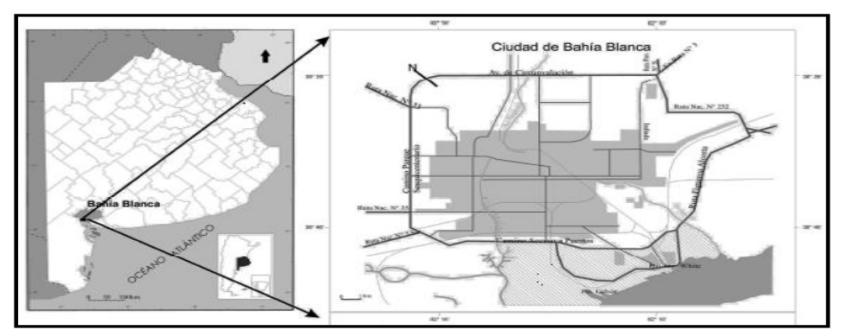

Figura 1. Ubicación geográfica del partido de Bahía Blanca (Ramborger, M.A., 2009).

Es una ciudad media por su tamaño demográfico, ya que el último censo arrojó la cantidad de 301.501 habitantes (INDEC, 2010) y un centro urbano de tamaño intermedio por sus funciones. Constituye un nodo de servicios especializados, particularmente en educación y salud, lo que se complementa con otros servicios y actividades comerciales diversificadas. Es un centro regional relevante en el sudoeste de la provincia de Buenos Aires por sus actividades portuarias, industriales y de servicios, en especial 
en lo que respecta a la oferta educativa y de salud, de alta calidad y nivel de excelencia. Desempeña un rol tradicional como centro comercial y de servicios para un amplio ámbito regional, lo que se traduce en un predominio de los empleos relacionados con el sector terciario. Más aún, en su carácter de "nodo" geográfico se fueron fortaleciendo las ocupaciones vinculadas con el funcionamiento de ciertas actividades de servicios básicas (electricidad, gas natural, telefonía).

El sector comercial, está ampliamente diversificado y presenta una destacada participación en la economía local. El sector de venta minorista está orientado principalmente al mercado local. Desde fines de la década del ' 90 se han radicado grandes superficies comerciales de venta, transformando las prácticas comerciales y generando nuevas alternativas de compras a los consumidores. El sector servicios explica casi el $40 \%$ del valor agregado generado en la localidad, destacándose los servicios empresariales, inmobiliarios y de alquiler (16.33\%), los de almacenamiento, comunicaciones y transporte (8.75\%), los vinculados a la educación (4.50\%) y a la salud (3.39\%); todos ellos se encuentran asociados a la dinámica del sector industrial de la ciudad y a la demanda del resto de las localidades de la región (Municipalidad de Bahía Blanca, 2017).

\section{Bahía Blanca: Un panorama de su actividad turística}

Bahía Blanca ofrece una diversa oferta vinculada a la actividad cultural, a los acontecimientos programados y a los espectáculos tanto de índole deportivo como teatral. Su condición de espacio de servicios y recreación, constituyen una verdadera fortaleza, ofreciéndole al visitante y residente la oportunidad de disfrute del tiempo de ocio, compras, entretenimientos, gastronomía, oferta hotelera, paseos al aire libre, peatonales, parques, espectáculos deportivos, cines, recitales, discos, pubs y vida nocturna otorgan un núcleo urbano que brinda un abanico de posibilidades para todos los gustos y edades. Gracias a su óptima accesibilidad, se comporta como nudo articulador de comunicaciones, facilitando la conexión con las principales ciudades del país a través de rutas, vías férreas y aéreas (Ver Figuras 2 y 3) confiriéndole el carácter de atractivo de su hinterland más cercano, otorgándole su sesgo funcional como centro de escala, recreación y servicios.

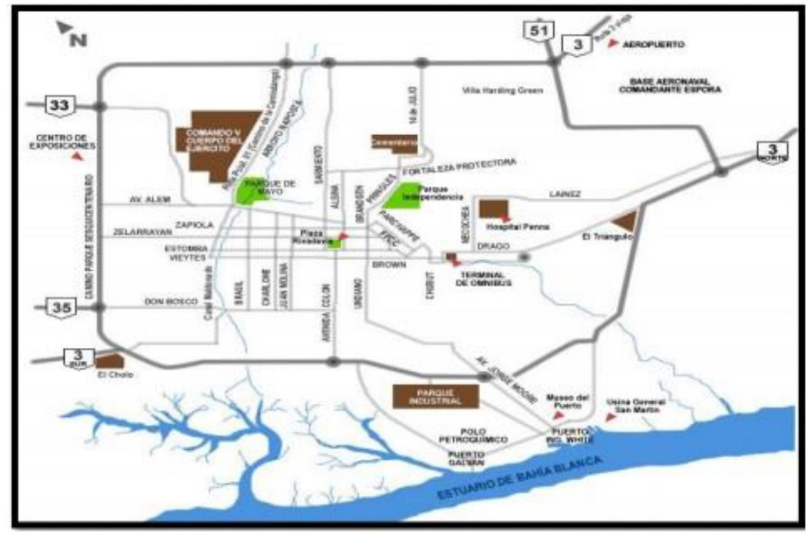

Figura 2. Accesibilidad vial a Bahía Blanca (Municipalidad de Bahía Blanca, 2014).

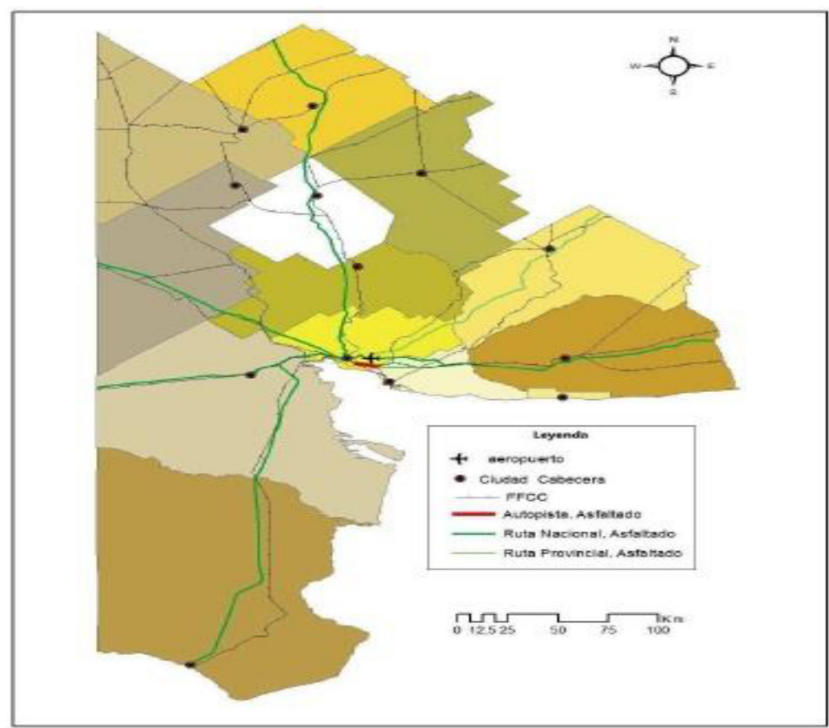

Figura 3. Redes de transportes (vial, ferroviaria y aérea) (Schroeder, R., 2011).

Asimismo, la ciudad es anfitriona de encuentros programados, deportivos, académicos, exposiciones, reuniones de negocios, y ferias, caracterizando un valor agregado de saberes especializados: Altas casas de Estudios como las Universidades Nacionales: del Sur y Tecnológica, Institutos Privados y Públicos, y Centros de Investigaciones 
Especializadas que, sumados a la diversidad de Colegios Profesionales, encuentran un espacio de producción que la posicionan como Sede de Turismo de Reuniones. Sus ventajas comparativas y competitivas la distinguen en el escenario provincial, nacional y mundial, concibiendo las potencialidades que le permiten impulsar el desarrollo de este tipo de producto con el mayor de los éxitos.

\section{Un segmento prometedor: El turismo de reuniones}

El turismo de reuniones, se desarrolla en la localidad de Bahía Blanca gracias a la disponibilidad de equipamiento e infraestructura de calidad, diversidad de atractivos y personal altamente capacitado para cubrir las necesidades de un mercado exigente. Actualmente la ciudad cuenta con sedes académicas y equipamiento para desarrollarlo (Tabla 1).

\section{Tabla 1. Sedes académicas y equipamiento.}

\begin{tabular}{|c|c|c|c|}
\hline Sedes académicas & Salas & Capacidad & Datos de contacto \\
\hline Biblioteca Rivadavia & 2 & 450 & 02914554055 \\
\hline Cámara arbitral de cereales & 3 & 420 & 02914560140 \\
\hline Club Argentino & 7 & 1010 & 02914520211 \\
\hline Consejo Profesionales Ciencias Económicas & 2 & 210 & 02914534070 \\
\hline Conicet & 8 & 560 & 02914861666 \\
\hline Instituto Superior Juan XXIII & 2 & 400 & 02914562117 \\
\hline Municipalidad de Bahía Blanca & 2 & 335 & 02914594000 \\
\hline Universidad Nacional del Sur & 4 & 900 & 02914595100 \\
\hline Casa de la Cultura & 4 & 170 & 02914595100 \\
\hline Centro Histórico y Cultural UNS & 4 & 220 & 02914595100 \\
\hline $\begin{array}{l}\text { Universidad Tecnológica Nacional } \\
\text { Teatros }\end{array}$ & Teatros & 330 & 08914555220 \\
\hline Teatro Municipal & 2 & 816 & 02914563973 \\
\hline Teatro Don Bosco & 2 & 960 & 02914556498 \\
\hline Teatro Rossini & 1 & 500 & 02914550686 \\
\hline \multicolumn{4}{|l|}{ Salones para eventos } \\
\hline EIS & 1 & 280 & 02914523615 \\
\hline Realce & 2 & 280 & 02914549195 \\
\hline Revoque Eventos & 2 & 340 & 02915731521 \\
\hline Stradivarius & 2 & 620 & 02914558888 \\
\hline Sueños & 2 & 800 & 02914540881 \\
\hline Palihue Rugby Hockey Club & 1 & 150 & 02914524514 \\
\hline Asociación de empleados de Comercio & 3 & 3300 & 02914562960 \\
\hline Bahía Blanca Plaza Shopping & 9 & 2810 & 02914594100 \\
\hline Salón Sindicato Luz y Fuerza & 1 & 1100 & 02914546040 \\
\hline Salón Sindicato Obras Sanitarias & 1 & 110 & 02914565305 \\
\hline Complejo Punto Aparte & 2 & 290 & 02914861302 \\
\hline Club El Nacional & 1 & 100 & 02914524091 \\
\hline \multicolumn{4}{|l|}{ Espacios para Ferias } \\
\hline $\begin{array}{l}\text { Predio ferial Corporación del Comercio } \\
\text { Hoteles }\end{array}$ & 5 & 4710 & 02914522112 \\
\hline Aparto Hotel Orión & 1 & 80 & 02914513505 \\
\hline Hotel Argos & 5 & 309 & 02914550404 \\
\hline Hotel Austral & 5 & 292 & 02914561700 \\
\hline Hotel Bahía & 1 & 50 & 02914553050 \\
\hline Hotel Land Plaza & 7 & 336 & 02914599000 \\
\hline Parador Austral & 3 & 80 & 02914861400 \\
\hline
\end{tabular}

Fuente: Gambarota, D. (2017), en base a datos de la Municipalidad de Bahía Blanca. 
En síntesis, la localidad de Bahía Blanca posee 90 salas disponibles para la realización de congresos y convenciones, con una capacidad total en salones de 23.538 personas. En el año 2014, Bahía Blanca ingresó por primera vez, por las reuniones registradas durante el 2013, en el Ranking Mundial de Países y Ciudades Sede de Eventos que anualmente elabora la Asociación Internacional de congresos y convenciones ICCA (International Congress and Convention Association). Con un total de seis eventos, la ciudad obtuvo el puesto 74 entre las ciudades latinoamericanas y 328 a nivel mundial. El área de turismo, viene trabajando sostenidamente en relación a este proyecto, tanto desde el contacto cotidiano con los potenciales organizadores, como desde la asistencia en destino mediante stand de informes turísticos, folleterías y visitas guiadas a los visitantes.

Durante el año 2013, desde la mencionada área, se registraron 83 acontecimientos programados, de los cuales 6 fueron internacionales. Los mismos fueron organizados por la Universidad Nacional del Sur, Universidad Tecnológica Nacional, Puerto de Bahía Blanca, INTA (Instituto Nacional de Tecnología Agropecuaria), Institutos dependientes de la Universidad Nacional del Sur y APELL (Programa de Concientización y Preparación para Emergencias a Nivel Local).

\section{Una exploración de los principales atractivos bahienses}

Bahía Blanca posee una amplia diversidad de patrimonio arquitectónico y cultural en su haber, guardando el valor y el testimonio de la cultura bahiense, le imprimen al paisaje urbano su sesgo identitario, atributos que no pasan inadvertido por aquellos visitantes que buscan nuevos destinos, ávidos de conocer culturas diferentes y formas de vida.

Se ofrece al visitante una interesante producción y agenda artístico cultural, conformada por 16 museos y 5 salas teatrales, entre las que se destaca el Teatro Municipal, inaugurado en el año 1913, construcción que forma parte del Patrimonio Arquitectónico.

Entre los acontecimientos programados de mayor relevancia local encontramos: la Fiesta de San Silverio y Fiesta
Nacional del Camarón y el Langostino, en White (Fiesta de alcance y jerarquía Nacional), Maratón de Reyes, Feria de la Producción, el Trabajo, el Comercio y los Servicios del Sur Argentino, Feria Nacional del Artesano y Fiesta Nacional del Básquet, entre otras.

El paseo portuario es el principal motivador para aquellos que desean el contacto con el mar, y también con el mundo industrializado. A tan sólo $5 \mathrm{~km}$, del centro de la ciudad se puede visitar el Primer Puerto Autónomo de Aguas Profundas del país, el Parque Industrial, Polo Petroquímico y la localidad de Ingeniero White, sitio ideal para escuchar historias de inmigrantes, arquitectura ferroportuaria, casas de chapa y madera, historias de tango, gastronomía portuaria, tradiciones y fiestas populares, constituyen el reflejo de la cultura de una comunidad con apego a su territorio.

A poca distancia, el paisaje natural de la "Reserva natural de usos múltiples Bahía Blanca, Bahía Falsa, Bahía Verde", compuesto por un grupo de islas permite tomar contacto con la naturaleza, flora y fauna autóctona, caracterizan un sitio de inigualable riqueza, pesca deportiva, avistaje de fauna, safaris fotográficos y visitas interpretativas, entre otras; son algunas de las alternativas que ofrece este sitio de singularidades especiales, ofreciendo la posibilidad de realizar prácticas ecoturísticas.

Distante a $15 \mathrm{~km}$ de la ciudad de Bahía Blanca, con una población de 8.716 habitantes (INDEC, 2010), y como si el tiempo no hubiese pasado, se encuentra la localidad de General Daniel Cerri, fundada el 27 de mayo de 1876, caracterizada por la tranquilidad, seguridad, riqueza cultural y natural. Las posibilidades recreativas que ofrece el sitio, cargan de connotaciones positivas el desarrollo turístico recreativo del sector, basado en la diagramación de circuitos culturales organizados en función a su acervo histórico y patrimonio industrial. El área de turismo del municipio ofrece hace varios años diferentes circuitos que permiten conocer la historia de la ciudad y los lugares más representativos, los cuales se encuentran detallados en el siguiente cuadro (Tabla 2 ). 
Tabla 2. Circuitos turísticos de la ciudad de Bahía Blanca.

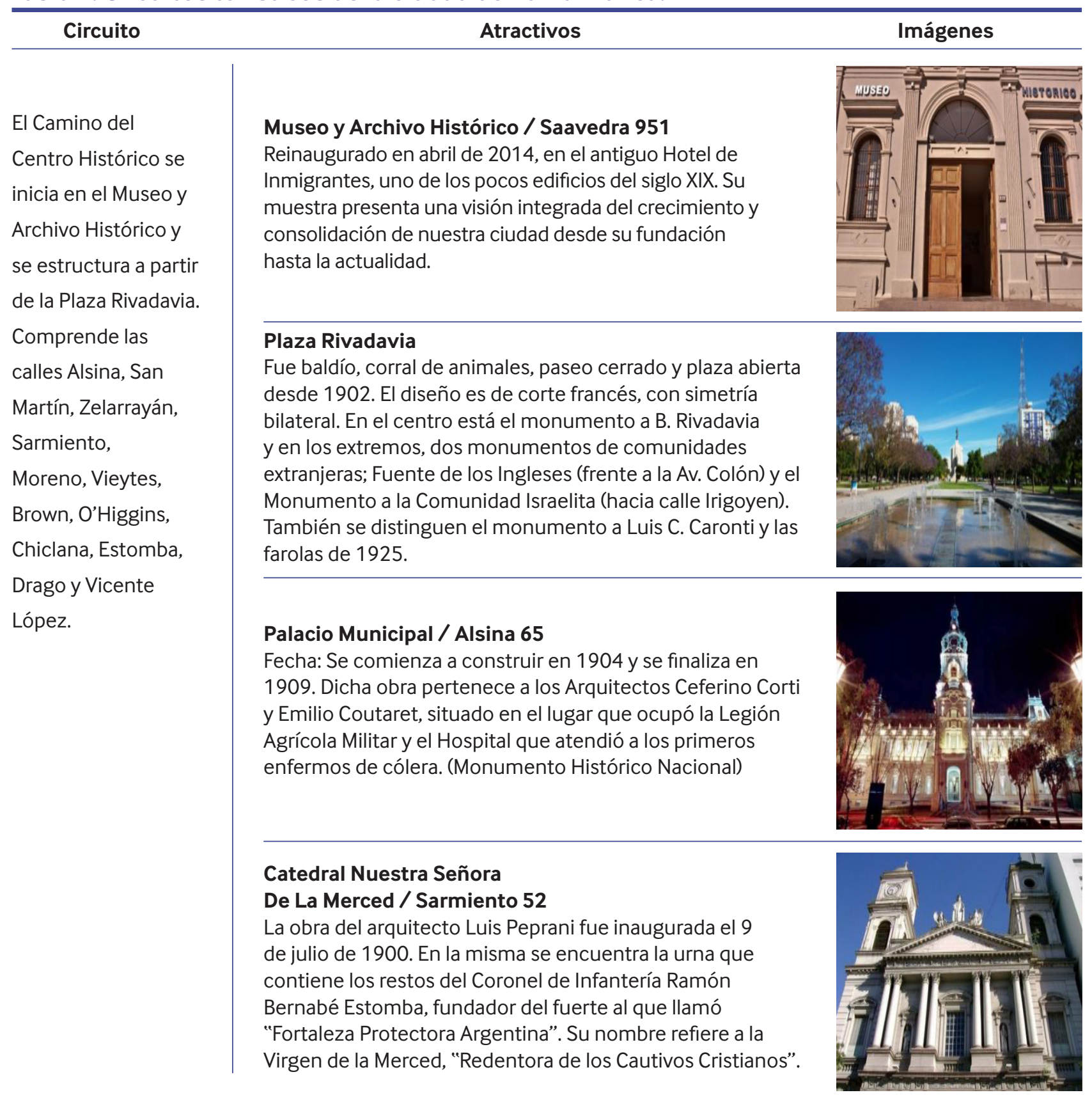




\section{Ex Diario La Nueva Provincia / Sarmiento 54}

El diario fue fundado por Enrique Julio. El edificio actual data de 1928. El proyecto para la construcción perteneció al Ingeniero Adalberto Pagano siendo la empresa constructora $\mathrm{N} \mathrm{y}$ $\mathrm{G}$ Pagano. Actualmente funciona el Colegio de Abogados.

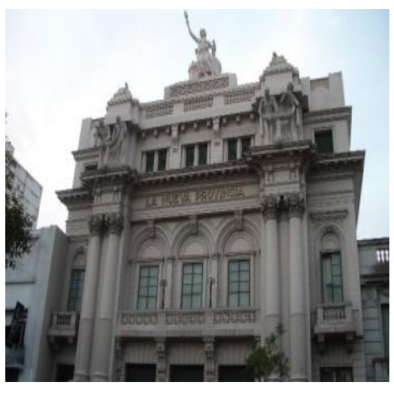

\section{Ex Banco Provincia / Alsina 43}

Fecha: 1916 y 1918. Arquitecto: Luis B. Roca y obra de los contratistas Andrés Diotto y Vicente Spinedi. El Banco funcionó hasta 1982, actualmente funcionan oficinas municipales. (Monumento Histórico Nacional)

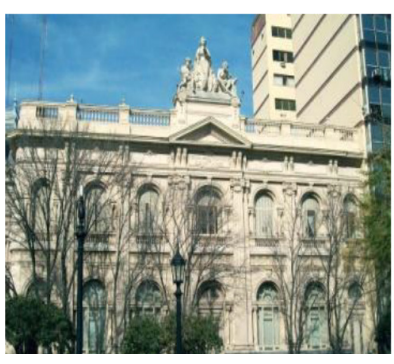

\section{Ex Banco Alemán Transatlántico / Sarmiento y Estomba}

Construido en 1911 por el arquitecto Carlos Nordmann autor de otras obras emblemáticas como la Galería Peuser (1916) en calle 0 `higgins, "Torreón del Monje” en Mar del Plata y Estancia la Ventana en Tornquist, entre otros. Un dato curioso es que en su época de apogeo los habitantes bahienses se acercaban a ver las cortinas de enrollar metálicas ya que fue el primer edificio de la ciudad que contó con este novedoso sistema. Hoy es sede del Honorable Concejo Deliberante.

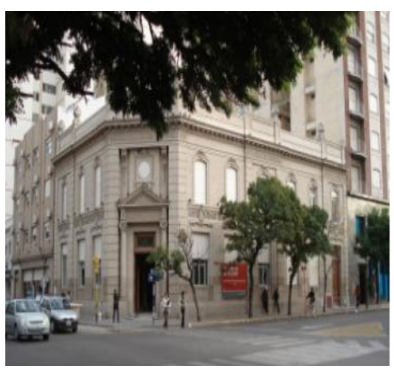

\section{Banco Nación / Estomba y Moreno}

Fecha: 1921. Arquitecto: Juan Ochoa - Constructor: Baldasarre Zani.

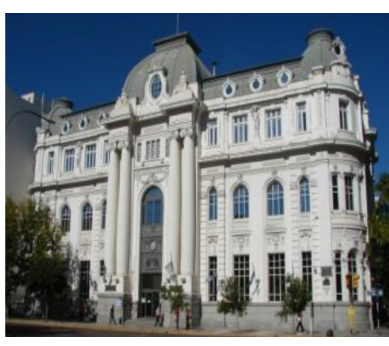

\section{Aduana / Estomba y Avenida Colón}

Fecha: 1903. Inicialmente fue sede del Banco de la Nación Argentina. Arquitecto: Alejandro Christophersen - Constructores: Boggini y Gerardi.

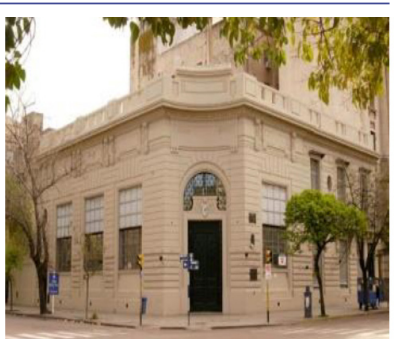




\section{Ex Banco Español / Chiclana y Avenida Colón} Fecha: entre los años 1904 a 1908 - Arquitecto: Carlos Agote y su constructor Antonio Gerardi Actualmente funciona la Bolsa de Comercio.

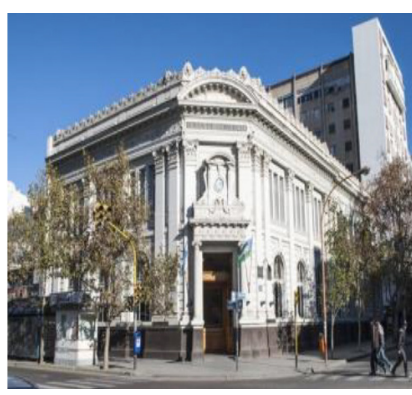

\section{Ex Banco Hipotecario Nacional / Avenida Colón y Vicente López}

Fecha: entre 1923 a 1926 - Ingeniero: Alejandro Ortúzar y Arquitecto: Juan Ochoa su constructor fue Santiago Teddi.

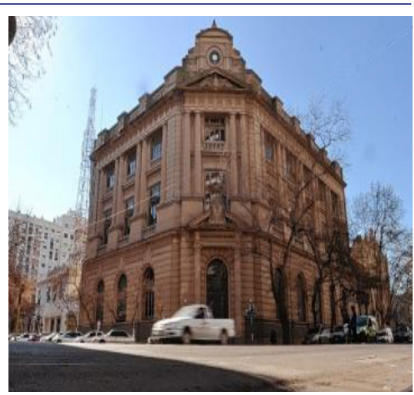

Palacio De Tribunales / Estomba 32

Fecha: se empieza a construir en abril de 1926 y se inaugura el 11 de abril 1928. Arquitecto:

Enrique Quinke - Constructor: Justo José Querel.

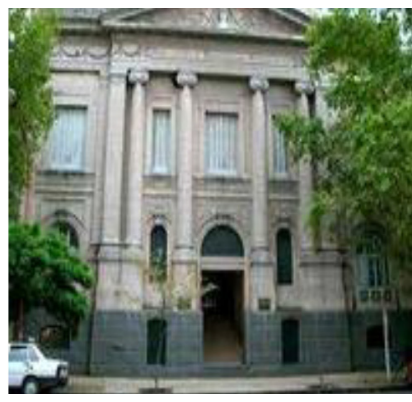

\section{Biblioteca Rivadavia / Avenida Colón 31}

Fecha 1930. Arquitecto: Ernesto Giraud - Constructor: José Querel. La Asociación Bernardino Rivadavia fue creada en 1882. La Biblioteca es además un espacio cultural donde se realizan diferentes actividades como conciertos, talleres y exposiciones de diferentes muestras abiertas al público. (Monumento Histórico Nacional)

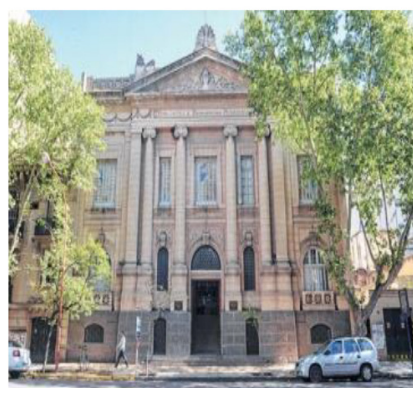

Club Argentino / Avenida Colón 67

Fecha: 1910. Arquitecto: Alberto Coni Molina - Constructor: Nicolás y Gerardo Pagano. (Monumento Histórico Nacional)

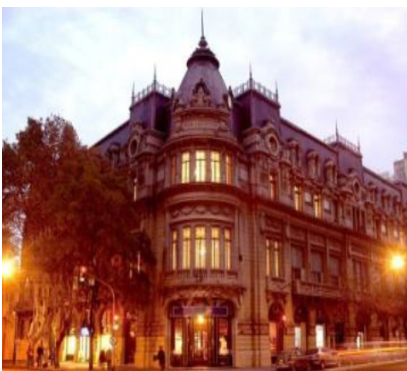




\section{Escuela N² / Vieytes 51}

Fecha: 1928. Arquitecto: Julio Gazzari - Construtor: Santiago Teddi.

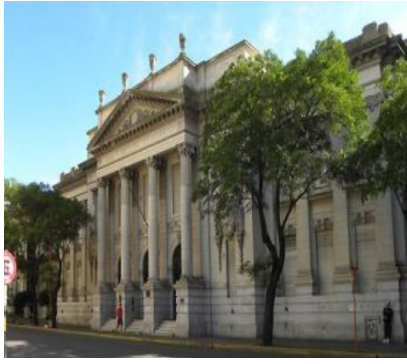

Camino de los Fortines, Laneras y Frigoríficos La localidad de Gral. Daniel Cerri, reúne en sus calles patrimonio histórico e industrial. Sus orígenes vinculados al Fortín Cuatreros y su rol de pueblo industrial a través del procesamiento de lanas y carnes a principios del siglo XXI le dieron una singular fisonomía.

Este camino recorre el Fortín Cuatreros, la casa de ramos generales, los bares, colonias de obreros, el cine, la parroquia, los clubes, la estación, la lanera y los frigoríficos; además de la Ecoplanta, símbolo de la actualidad.

\section{Correos y Telégrafos / Moreno 34}

Fecha: se comenzó a construir en 1919 y se inauguro en 1928. Arquitecto: Van Dorsen - Constructor: Roberto Cartagna - Dirección del proyecto: Luis de Ochagavía. (Monumento Histórico Nacional).

\section{Museo Fortín Cuatreros / Alvarado y Av. Plácida Pernicci}

En este museo se expone una muestra sobre el General Daniel Cerri, la creación del Fortín Cuatreros y las relaciones interétnicas. Por otra parte imágenes y objetos sobre el primer pueblo industrial del sudoeste bonaerense con sus principales actividades, el procesamiento de la lana y la carne.

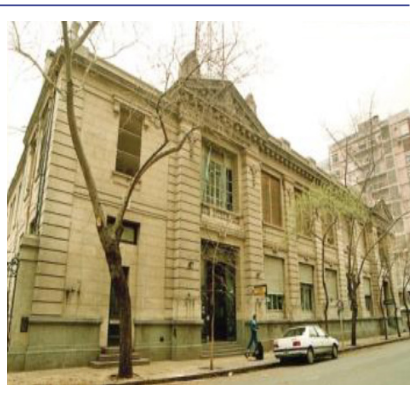

\section{Iglesia San Miguel Arcángel / Gurruchaga 440}

Inaugurada el 3 de septiembre de 1905 y situada en terrenos cedidos por Ernesto Tornquist, fue levantada por los Salesianos a pedido de los obreros del frigorífico La Negra-Sansinena. El edificio se caracteriza por contar con reminiscencias renacentistas.
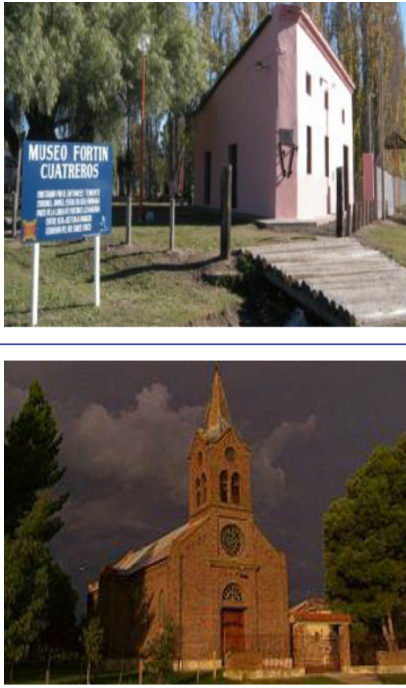

Cine y Pensión Voglino / Av. Rodríguez Peña y Belgrano Desde principios de siglo XX, fue restaurante, café y billar, alojamiento y cine. Su apertura tuvo por objeto hospedar operarios y jefes provenientes de Capital Federal y Gran Bs As que arribaron para construir el frigorífico Sansinena. En el salón de la esquina se encontraba el bar, desde allí se accedía al comedor y a la cocina. Las películas se proyectaron en forma de diapositivas, posteriormente el cine mudo, el cine con motor y por el cine sonoro.

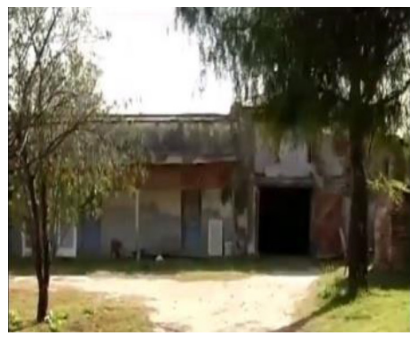

Julio - Diciembre 2018 | 145 


\section{Lanera Argentina / AlvarezJonte entre Belgrano y 25 de mayo}

El edificio data de 1905. Su característica arquitectónica nos remonta a las ciudades industriales inglesas de los siglos XVIII y XIX. Allí funcionó el lavadero de lanas y peladero de pieles Santa María, de la firma Soulas y Familia, una de las industrias más importantes de la región y el país en su tipo. En 1929 pasa a llamarse Lanera Argentina S.A., denominación que mantuvo hasta 1994. En la actualidad el edificio fue puesto en valor con otras funciones por una empresa local.

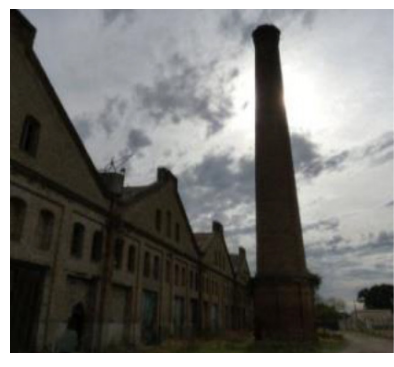

\section{Ex Frigorífico Cap Cuatreros / Alvarez Jonte y Belgrano} Al lado de la Lanera Argentina se levantó el frigorífico Sansinena. En 1901 la Compañía Sansinena compró 2000 hectáreas en Cuatreros, propiedad por entonces de Ernesto Tornquist. En ese sitio se construyó el frigorífico, puerto y playa de maniobras ferroviarias, las que son inauguradas en octubre de 1903.

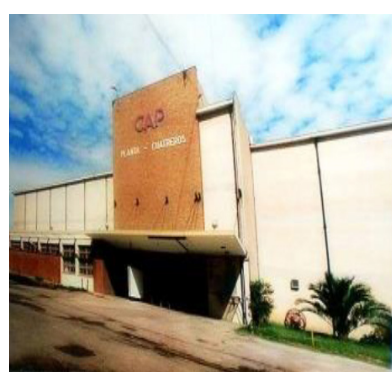

\section{Estación Aguará / 25 de Mayo y Granaderos}

Inaugurada en el año 1912, la estación Aguará del Ferrocarril Buenos Aires al Pacífico se transformó en nudo estratégico para el desarrollo económico e industrial de la localidad. Desde allí se desembarcaba hacienda para el frigorífico Sansinena en el pueblo Cuatreros (hoy Cerri), contaba con casa de familia para el jefe de la estación y personal auxiliar, galpón de carga y descarga y desembarcadero de animales.

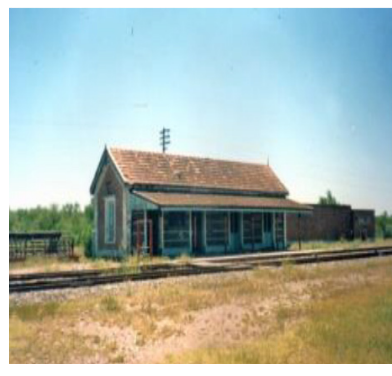

\section{Club de Pesca y Náutica General Daniel Cerri} Inaugurado el 30 de enero de 1970, se transformó en sitio elegido para los amantes de la pesca deportiva.

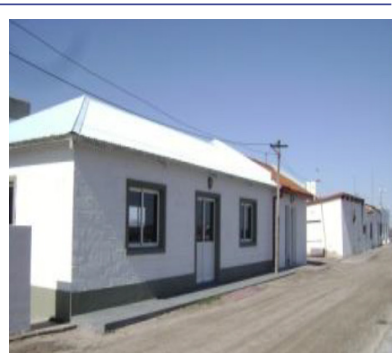

\section{Ecoplanta / Juana Azurduy y Artigas}

Fundada el 11 de abril del 2000 y ubicada en el sector norte de la localidad intenta minimizar la problemática de los residuos recuperando aquellos que pueden volver a ser productivos (inorgánicos) a través del reciclado y la transformación de orgánicos en compos y lombricompuestos. De esta forma se colabora en la prolongación de la vida útil de los rellenos sanitarios y la toma de conciencia ambiental.

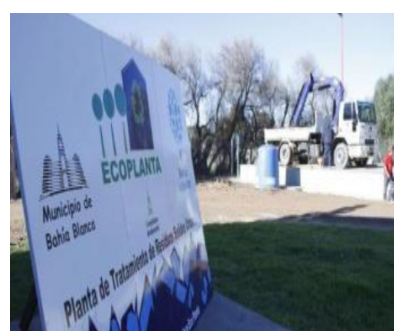


Camino de los Puertos Historias de inmigrantes, tango y conzonetas, arquitectura ferroportuaria, grandes buques cerealeros, containers, art decó, casas de chapa y madera, gastronomía portuaria, gaviotas cangrejeras, delfines franciscana, chimeneas, petroquímica, tradiciones y fiestas populares forman parte de la vida cotidiana de la localidad de Ingeniero White. Este camino permite tomar contacto con el mar, una comunidad inmigrante y su territorio en la localidad que alberga el Primer Puerto Autómono de aguas profundas del país.

\section{Teatro de Ingeniero White / Av. San Martín 3619}

Construido por la Sociedad Italiana de Socorros Mutuos el 4 de julio de 1925 y reinaugurado el 23 de noviembre de 1995 , deseando proteger la identidad de la localidad del olvido y del desinterés, recibiendo de esta manera el nombre de "Teatro de Ingeniero White".

\section{Museo del Puerto / Av. Guillermo Torres y Cárrega}

Creado en 1987, ocupa el primitivo edificio de la Aduana. Se exhiben objetos de uso cotidiano de otras épocas, con salas adaptadas que permiten conocer el modo de vida de aquellos pobladores que llegaron desde otras naciones en busca de nuevos horizontes laborales. "La cocina", simboliza el sitio de encuentro familiar y las delicias se pueden disfrutar durante los fines de semana, en donde las distintas colectividades preparan sus platos típicos.

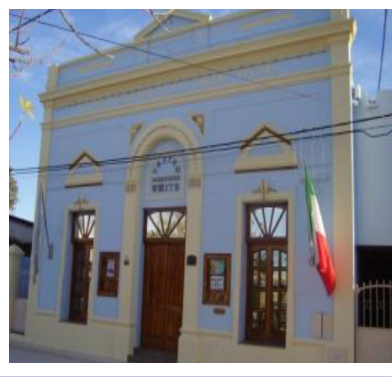

\section{Ex Usina General San Martin / Av. Juan Bautista Justo 3885}

Fue inaugurada en el año 1932. Se trata de una gigantesca construcción de hormigón armado erigida sobre terrenos ganados al mar. La fachada representa un auténtico castillo de estilo Tudor, sin embargo poco tiene que ver con el pasado medieval europeo. Su remate con la escultura de "San Jorge y el dragón", obra del artista italiano Troiano Troiani fortalecen su imagen. La misma proveyó de electricidad a la ciudad durante 56 años.

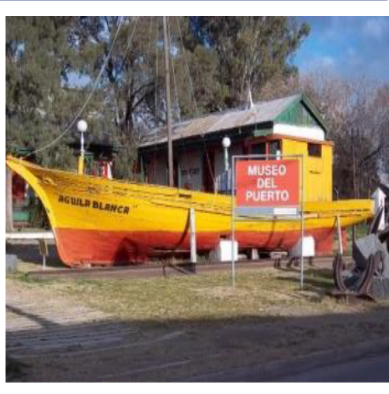

\section{Primera Usina del Puerto}

Inaugurada en 1908 y propiedad de la empresa Ferrocarril del Sud, fue construida por los Ingenieros José Rión y Alberto Pringles quien tuvo a cargo la dirección de la obra. Construido en sobrio estilo inglés, el edificio presenta características excepcionales no sólo por sus dimensiones, sino por su estética y funcionalidad. Resalta en el paisaje portuario por su chimenea (50 metros) y construcción de ladrillo visto.

\section{Central Termoeléctrica Luis Piedra Buena / Ruta 252}

Desde cualquiera de las rutas que convergen a Bahía Blanca se recorta a la distancia una figura que es ya familiar: la majestuosa silueta de la chimenea de la termoeléctrica Luis Piedra Buena, con sus 152 metros de altura, que ha modificado el paisaje bahiense. Su puesta en marcha fue en el año 1989 y esta interconectada al sistema nacional de electricidad.
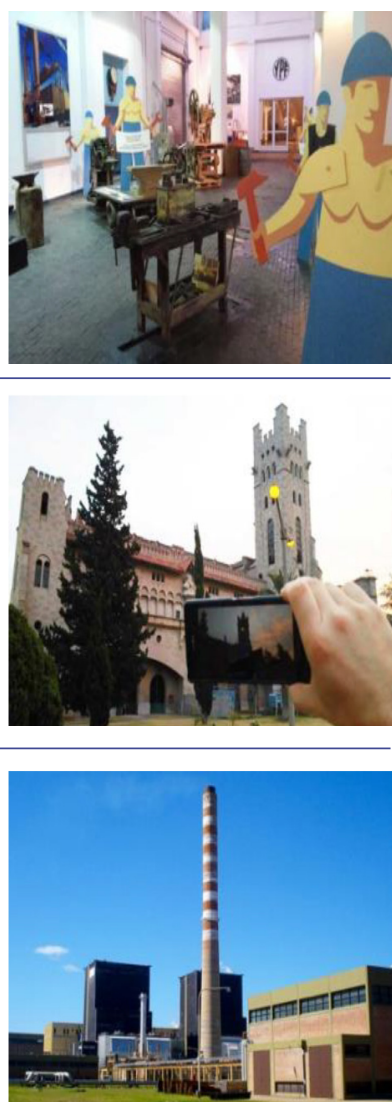
Camino de los

Barrios y Parques

El sector estructurado por las Avenidas Alem y Urquiza caracteriza la ciudad universitaria, recreativa, deportiva y nocturna. Casonas con estilo, teatro, parques, barrios representativos, edificios emblemáticos, paseos al aire libre a la vera del Arroyo Napostá, pubs, restaurantes y confiterías exponen una ciudad que se ofrece con una amplia variedad de opciones de esparcimiento. Los Parques de Mayo e Independencia, son utilizados por los habitantes como lugares

\section{Paseo Portuario}

Construido por el Consorcio de Gestión del Puerto de Bahía Blanca se ha transformado en un sitio ideal para el esparcimiento y la recreación. Cuenta con el equipamiento necesario para contemplar el mar y las actividades náuticas. Jerarquizando el Paseo se puede observar la imagen de "San Silverio", Patrono de los Pescadores.

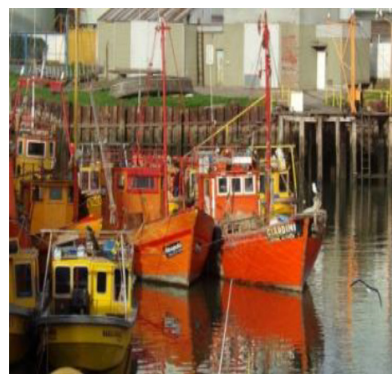

\section{Complejo Petroquímico y Parque Industrial}

Se instala a principios de los años 70 el complejo petroquímico transformándose en el más grande de Argentina. Uno de los elementos para el desarrollo de nuestra ciudad y su región, estrechamente ligado con el Puerto y el Complejo Petroquímico es el Parque Industrial ubicado al sur de la provincia de Buenos Aires, a $5 \mathrm{~km}$ del centro. Nació como propiedad de la Provincia de Buenos As y posteriormente fue transferido a la Municipalidad de Bahía Blanca.

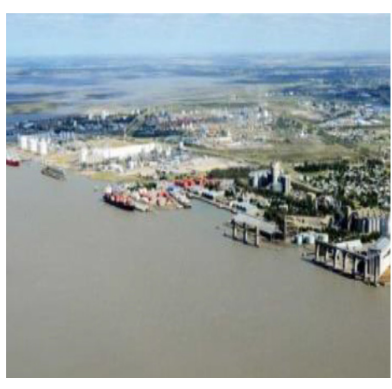

\section{Teatro Municipal / Alsina 425}

Es el más significativo de la ciudad. Ocupa el solar que da nacimiento a la Av. Alem. Inaugurado el 9 de Agosto de 1913, posee una capacidad para 850 personas. Cuenta con 6 salas de ensayo y diversos talleres. Está posicionado como uno de los diez teatros más importantes del país con un promedio de 300 funciones anuales. Es sede de la Orquesta Sinfónica Provincial y del Ballet del Sur. En el año 2011 fue declarado Monumento Histórico Nacional.

\section{Fundación Ezequiel Martínez Estrada / Av. Alem 908}

Lugar de residencia del escritor nacido en 1895 en la provincia de Santa Fe y radicado desde 1949 en Bahía Blanca. Recibió dos veces el Premio Nacional de Literatura y fue presidente de la Sociedad Argentina de Escritores. Entre sus obras se destacan "Radiografía de la Pampa", escrita en 1933, "Heraldos de la verdad" de 1958 y "Tres poemas del anochecer", publicada en 1964.
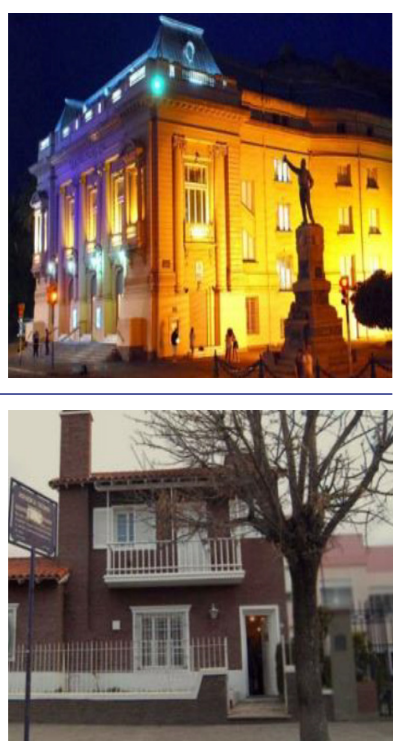

\section{Casa De La Cultura / Av. Alem 925}

Antigua casona colonial de principios del siglo XX otorgada a la administración de la Secretaría General de la Universidad Nacional del Sur. Es un espacio dedicado a actividades académicas y culturales, exposiciones, seminarios, actividades teatrales y musicales; cada año decena de artistas exhiben allí sus obras.

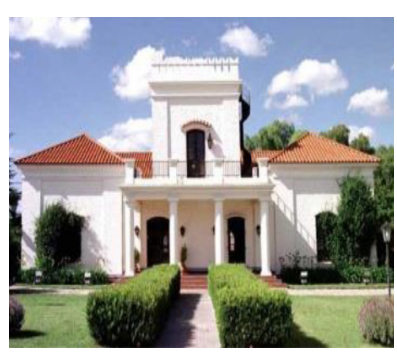


de descanso, recreación y realización de actividades deportivas complementando este paseo, que se impone a la hora de disfrutar de actividades a cielo abierto.

\section{Club Universitario / Av. Alem 1151}

El edificio fue construido en el año 1930 por Adalberto Pagano como sede del club Sociedad Sportiva. Hoy es una institución social y deportiva sin fines de lucro, conducida mediante una comisión directiva integrada por estudiantes universitarios. Se ubica dentro del predio de la Universidad Nacional del Sur, sobre Avenida Alem al 1100. Allí se desarrollan actividades deportivas y culturales para socios y público en general.

\section{Universidad Nacional del Sur / Av. Alem 1253}

Su origen se remonta al antiguo Instituto Tecnológico del Sur, creado en 1946. En 1956 se crea la Universidad Nacional del Sur, siendo la octava creada en el país. Por su nivel académico está ubicada entre las primeras cinco de Argentina. El edificio presenta columnas gigantes las que juntamente con las escalinatas de acceso realzan la fachada. Sobre el frente se halla una fuente cuyos capullos de mármol de carrara pertenecen a la escultora Lola Mora.
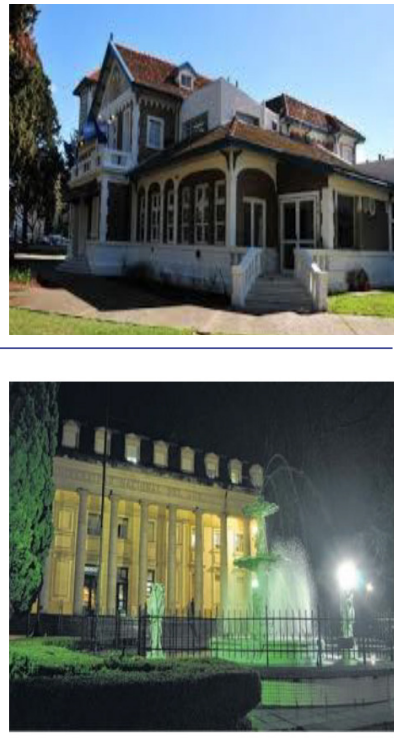

\section{Parque de Mayo / Av. Alem y Córdoba}

Creado a principios de siglo XX como "Barrio Adornado y

Parque Municipal" es uno de los espacios verdes y recreativos más importantes de la ciudad con una superficie de 60 hectáreas forestadas. Su nombre se debe al primer centenario de la Revolución de Mayo en 1910. Cuenta con cancha de fútbol, sóftbol, pista de salud, anfiteatro, bici sendas, juegos infantiles, pista de bicicross y skate, restaurantes tipo "carritos" y botes para pasear por el lago artificial.

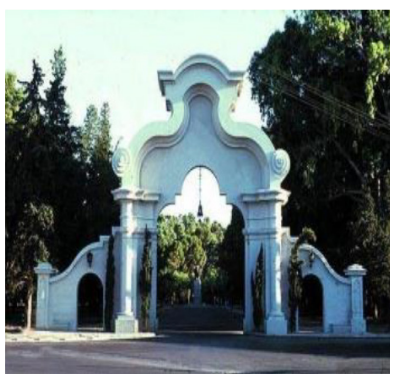

\section{Arroyo Napostá}

Cumplió un papel fundamental para el aprovechamiento de agua y como elemento defensivo; más tarde sus aguas sirvieron para regar quintas. Recorre el Parque y sigue su curso hacia su desembocadura en la bahía; en Av. Urquiza y Casanova comienza el entubado que finaliza en la Terminal San Francisco de Asís. Esta zona se ha transformado en un paseo durante el día y en una zona de gran actividad durante las noches por la presencia de pubs y restaurantes.

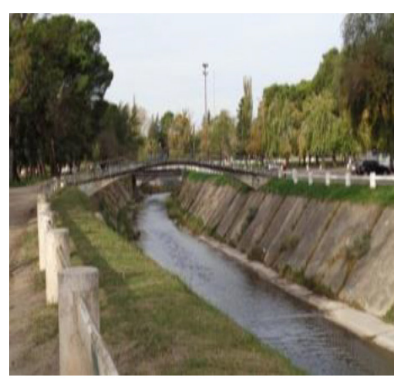




\section{Paseo de Las Esculturas}

Se encuentra emplazado en la Avenida Urquiza, sobre el entubado del Arroyo Napostá, y está ornamentado con obras creadas durante el $1^{\circ}$ Simposio Nacional de Escultura Monumental realizado en la ciudad en el año 1993.

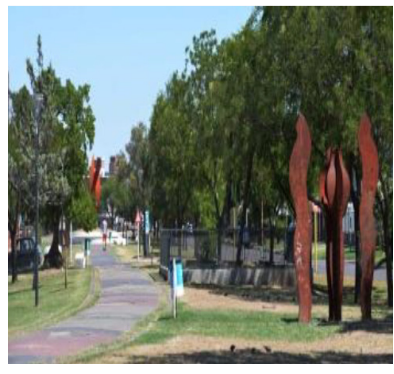

\section{Barrio Parque Palihue}

El Barrio Palihue debe su origen y su nombre al Club de Golf emplazado en terrenos aledaños al mismo barrio, y proyectado por el arquitecto Manuel Mayer Méndez hacia 1940. La institución deportiva fue bautizada con el nombre Palihue, derivado de dos palabras mapuches "pali", bola utilizada para el juego de la chueca y "hue", lugar, (por la cancha) donde se practicaba.

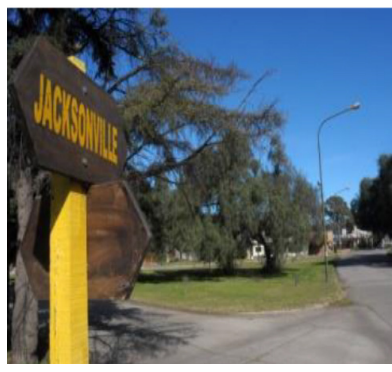

\section{Punto Panorámico / Av. Cabrera y Reconquista}

En el margen de la Avenida Cabrera, se forma un pequeño barranco, que permite al visitante apreciar la ciudad de Bahía Blanca desde otra perspectiva (70 mts. sobre el nivel del mar). Justo aquí, se encuentra la única colonia urbana de loros barranqueros (Cyanoliseuspatagonus) del mundo.

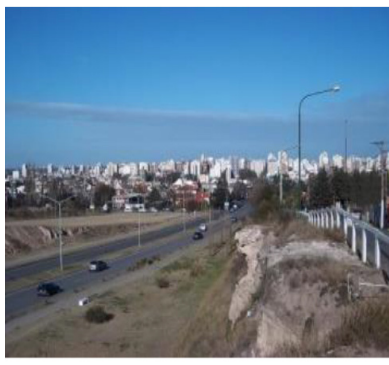

\section{Parque Independencia / Av. Pringles y Azara}

Ubicado sobre calle Azara y Avenida Pringles es el segundo espacio verde más importante de la ciudad. Con una superficie de 9 hectáreas el Parque es lugar elegido por los bahienses para realizar distintas actividades deportivas y recreativas, ofreciendo la posibilidad de visitar el Jardín Botánico que allí se encuentra desde 1995.

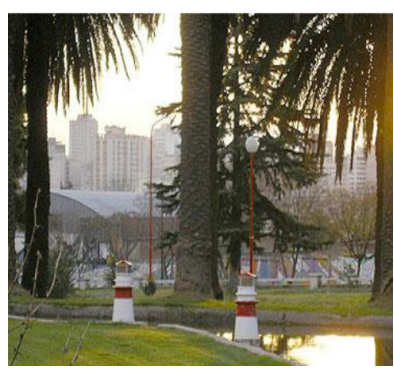




\section{Circuito}

Camino Bahía Capital del Básquet La gente de Bahía tiene entre sus pasiones el deporte en general y el básquet en particular, conformado un rasgo relevante de su identidad.

La historia del deporte, los principales clubes, jugadores e ídolos dan vida a este camino que se construye desde el 21 de mayo de 1910 cuando se llevó a cabo el primer partido de básquet en Bahía entre integrantes de la tripulación de barcos estadounidenses.
Atractivos Imágenes

\section{Club Estudiantes / Santa Fe 51}

Fue fundado en 1918. Su estadio Osvaldo Casanova, fue inaugurado en 1939 y reconocido como patrimonio arquitectónico de la ciudad. Por sus características fue declarado Sitio de Interés Cultural e Histórico de Bahía Blanca. Algunos de los jugadores más importantes que pasaron por el club son Alberto Cabrera, Jorge Faggiano, Hernán Montenegro, Juan Espil, Juan Ignacio Sánchez y Emanuel Ginóbili, estos últimos dos campeones olímpicos en Atenas 2004.

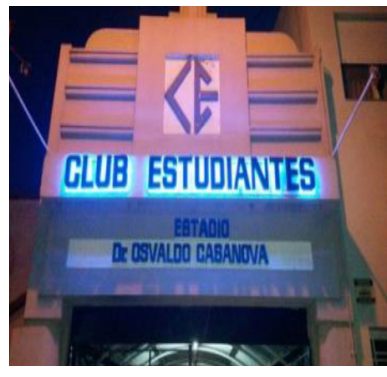

\section{Club Olimpo / Avenida Colón 888}

Es uno de los clubes más importantes y ricos en historia. Su estadio lleva el nombre Norberto Tomás en homenaje al jugador surgido de las divisiones menores del club que falleció en 1970 disputando un partido con la camiseta de Estudiantes. Fue inaugurado el 3 de Julio de 1971, día histórico para el básquet local, en donde la selección de Bahía Blanca le ganó al por ese entonces campeón del mundo Yugoslavia 78 a 75.

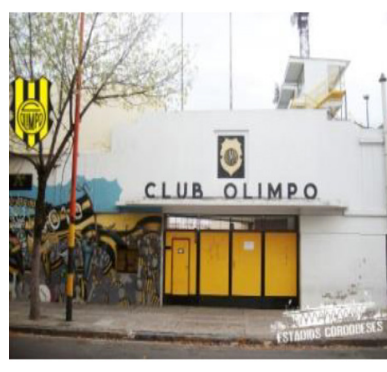

\section{Asociación Bahiense de Básquet (ABB) / 9 de Julio 62} Fundada en 1929 por los clubes Olimpo, Estudiantes, Liniers, Pacífico, Agor Cross y RiverPlate, posee un museo y archivo histórico de todos los jugadores federados que han practicado el deporte en los últimos 20 años, los trofeos conseguidos por Bahía Blanca en los torneos nacionales y provinciales y fotos de todos los jugadores bahienses que han integrado el seleccionado nacional.

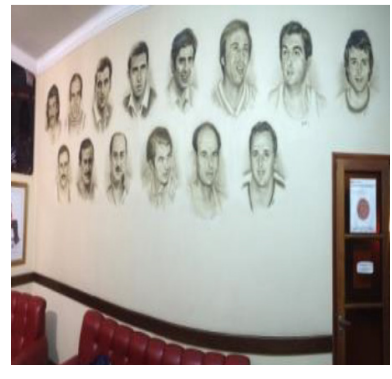

\section{Club Bahiense del Norte / Salta 28}

Club que nació el 1 de diciembre de 1975 de la fusión de dos pequeños clubes: Deportivo Norte y Bahiense Juniors y que fue cuna de grandes jugadores como Alejandro Montecchia, Emanuel Ginóbili y Juan Ignacio Sánchez, todos campeones olímpicos con la selección Argentina y cuna de grandes entrenadores como Oscar Sánchez, Pablo Coleffi y Sergio Hernández.

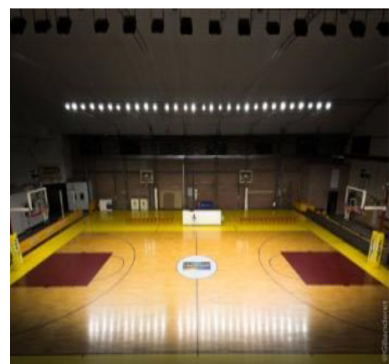


Camino del Riel

El ferrocarril

atraviesa la historia y

el paisaje urbano de

Bahía; su llegada en

1884, consolidó la

posición estratégica

y el desarrollo de la

ciudad.

En este camino

se transita por

la arquitectura

ferroviaria en

el trayecto que

articula la ciudad

por el puerto;

usina, elevadores,

mercados de acopio,

barrios, estaciones,

aduanas y el propio

puerto son reflejo

de una época donde se definió el rol de la ciudad como puerta de salida del granero del mundo.

\section{Museo del Deporte/ Peatonal \\ Luis María Drago 45, PB (Torre del Bicentenario)}

Ubicado en la Estación Sud e inaugurado el 8 de octubre de 2011 cuenta con recuerdos fotográficos, indumentaria, testimonios, trofeos, publicaciones gráficas de las glorias del fútbol, básquet, automovilismo, atletismo y el deporte en general. Uno de los ídolos del básquet bahiense, Atilio José "Lito" Fruet, trabajó intensamente para la concreción de este espacio y en la recopilación de gran parte del material que contiene en la temática del básquet.

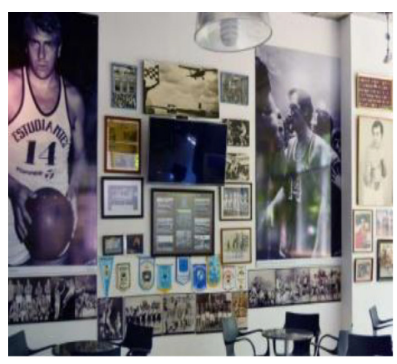

\section{Mercado de Concentración de Lanas, Frutos y Cueros "Victoria"}

Hacia principios de siglo XX los alrededores del Mercado Victoria constituían una de las zonas de la ciudad de mayor movimiento. Comenzó a construirse en 1897 y demandó una década de trabajo. Su función fue ser centro de almacenaje y venta de frutas y verduras, caracterizado por una arquitectura que deja ver la marcada influencia del ferrocarril y de las construcciones inglesas.

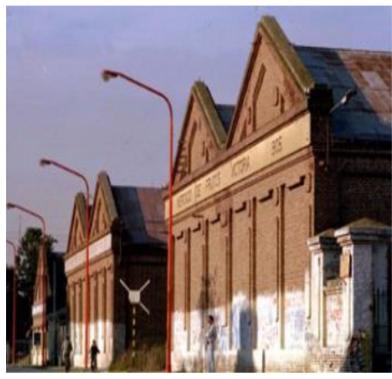

\section{Conjunto de Casas en calle Brickman}

La obra, a cargo del contratista local José Rión, incluyó la construcción de trece edificios, de los cuales nueve estaban terminados hacia mediados de 1908. El ladrillo visto conjuntamente con techos con pendiente y las chimeneas de ladrillo, caracterizan este tipo de arquitectura que por su armonía es reconocida como "Barrio Inglés" o "Nueva Liverpool".

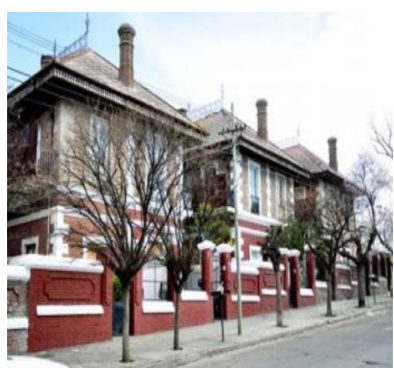

\section{Usina del BAP en Brickman y Donado}

Se empieza a construir en 1906 y en febrero de 1907 comienza a dar energía a los muelles de Puerto Galván. La misma proveería más tarde, al alumbrado público, particular, como así también al servicio de tranvías.

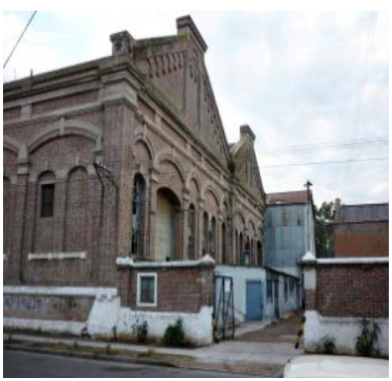




\section{Viejo Camino al Puerto}

Av. General Arias Viejo Camino al Puerto de Ingeniero White, con 3.000.000 de adoquines y un arbolado de eucaliptus donado por Agustín de Arrieta, se constituye en el primer camino hacia el puerto.

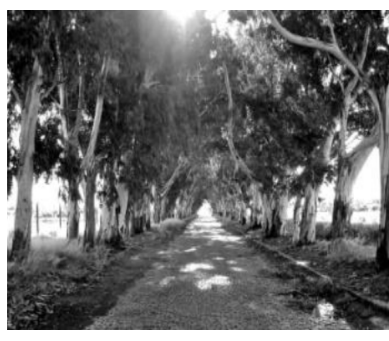

\section{Estación Spurr}

Ubicada entre la estación Bahía Blanca Sud, y la de Ingeniero White. La construcción que hoy podemos observar se comenzó a construir en el año 1927 liberándose al público en enero de 1928. Debe su nombre al marino Federico Spurr quien fuera Capitán del Puerto de Patagones y Comandante del transporte Villarino que realizaba viajes entre Buenos Aires, Bahía Blanca y Patagones.

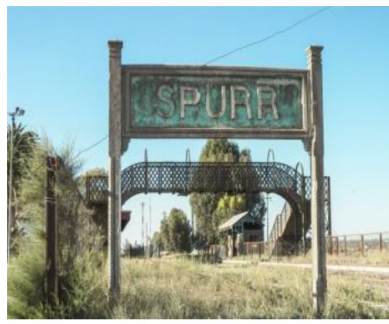

\section{Complejo de Puentes "La Niña"}

Es un conjunto de terraplenes y puentes que fueron construidos para salvar las vías que comunican la playa ferroviaria de la estación Ingeniero White, con los muelles y elevadores de granos, construidospor el ferrocarril Sud en ese sitio.

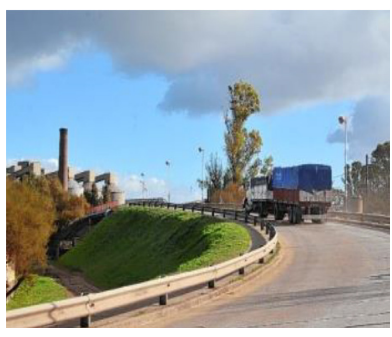

\section{Ex Aduana (Hoy Museo del Puerto)}

El edificio que data de 1907, está construido en chapa y madera, y apoyado sobre pilotes, siguiendo las típicas construcciones de otras obras del puerto. En 1987, el lugar fue restaurado, y a partir de esa fecha, comienza a funcionar el hoy Museo del Puerto, cuyo principal objetivo es mantener vigente la identidad del pueblo de Ingeniero White.

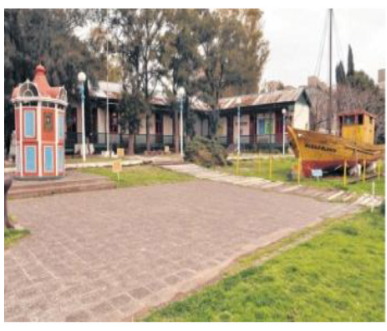

\section{Usina del Puerto}

Inaugurada en 1908 y propiedad de la empresa Ferrocarril del Sud, fue construida por los Ingenieros José Rión y Alberto Pringles que tuvo a cargo la dirección de la obra. Construido en sobrio estilo inglés, el edificio presenta características excepcionales, no sólo por sus dimensiones, sino por su estética y funcionalidad.

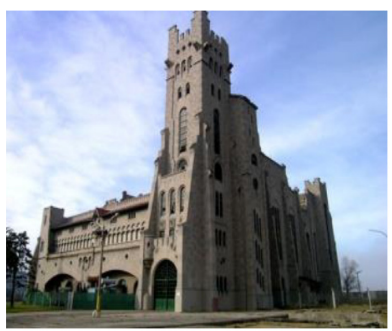


Camino de los

Museos

Más de 27 espacios

culturales, entre

museos, y salas de

exposiciones se

ofrecen al visitante

y residente a la hora

de conocer la historia

Bahiense y descubrir las expresiones

culturales de sus

artistas, muchos

cuentan la vida

de célebres

personalidades, mientras otros nos

muestran la vida

junto al mar de los

inmigrantes que con

trabajo y esfuerzo

acompañaron y

modelaron la Bahía

Blanca de hoy. Otros,

acompañan desde las

ciencias con

\section{Museo Taller Ferrowhite}

Inaugurado en el año 2004 e instalado en el edificio fuera el taller de la Usina General San Martín. Recrea la labor de los obreros ferroviarios.

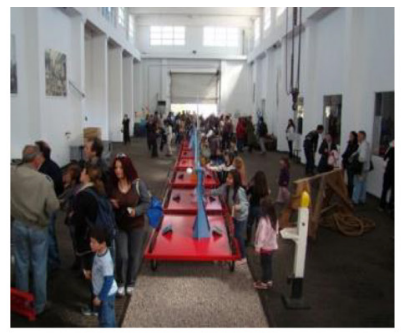

\section{Museo y Archivo Histórico de Bahía Blanca /} Saavedra 951 (EX. Hotel de Inmigrantes)

En su nueva sede, el museo cuenta con un ingreso dedicado a la historia del edificio, una sala principal organizada cronológicamente y un gabinete de curiosidades que atesora el corazón de la institución, y que el público podrá visitar. Nuevas comodidades, como un futuro bar, y un patio que los visitantes ya pueden disfrutar, permitirán realizar espectáculos y diferentes actividades que enriquecerán esta nueva etapa del Museo y Archivo Histórico de Bahía Blanca.

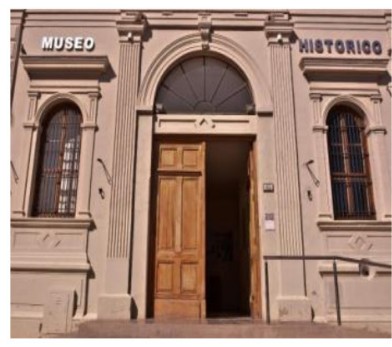

\section{Museo de Bellas Artes y Arte \\ Contemporáneo / Sarmiento 450}

Fue inaugurado el 11 de abril de 1995 y es el primer Museo de la Provincia dedicado exclusivamente a las manifestaciones del Arte Contemporáneo. Constituye un espacio de libertad, un foro abierto a la discusión y reflexión de la problemática cultural de nuestro tiempo. El trabajo del Museo de Arte complementa al de Bellas Artes de Bahía Blanca, abocado, casi con exclusividad, a la exposición de una importante colección de arte argentino.

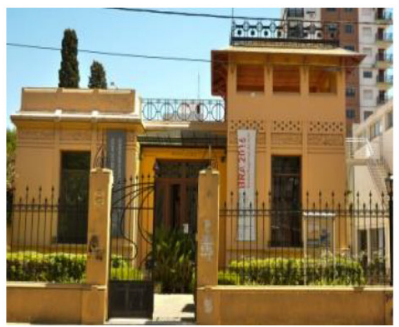

\section{Ferrowhite (Museo Taller) /}

\section{Juan B. Justo 3885 (Ingeniero White)}

Ferrowhite es un lugar en el que las cosas, además de ser exhibidas, se fabrican. Herramientas del ferrocarril y el puerto son el punto de partida para intentar comprender cómo se organizaban los talleres en los que esas herramientas eran utilizadas, cómo eran el orden y los conflictos de la sociedad a la que servían, y qué tal resultan, en comparación, las cosas hoy.

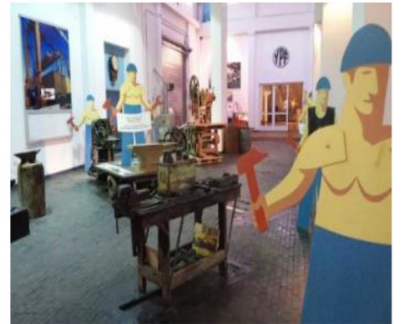




\section{Circuito}

Atractivos

Imágenes

novedosas

exposiciones de

Dinosaurios y

química, mientras

que el arte

Bahiense actual y

contemporáneo,

busca su espacio en

el centro de la ciudad

y en las casas de los

artistas. Otros nos

hacen recorrer la

historia, y en algunos,

observamos objetos

de los pueblos

originarios como así

también pequeños

fortines, mientras

que en el puerto la

historia del ferrocarril

se traduce en salas

que nos remontan a

un pasado vinculado

al progreso.

Historias y relatos de aviones, hangares, y de nuestras Malvinas

Argentinas, se

visualizan a través de salas especialmente adaptadas para que su visita se convierta en una experiencia inolvidable.

\section{Museo del Puerto / Guillermo Torres 4121 (Ingeniero White)}

El museo propone un recorrido por la historia y el presente del puerto y pueblo de Ing. White, que implica todo el cuerpo: en cada una de las salas la historia se puede ver, escuchar, tocar. ¿Cómo?: en una olla cachada está la economía mundial, en una torta se prueba la expansión del polo petroquímico, en un malvón plantado en una botella de lavandina están las privatizaciones de los ` 90.

Museo de Ciencias / Castelli 3702 (Parque de la Ciudad) Es un espacio dinámico e interactivo que pretende implementar formas nuevas y efectivas para popularizar las más variadas ramas de las ciencias y los temas relacionados con la protección y el uso sustentable del medio ambiente.

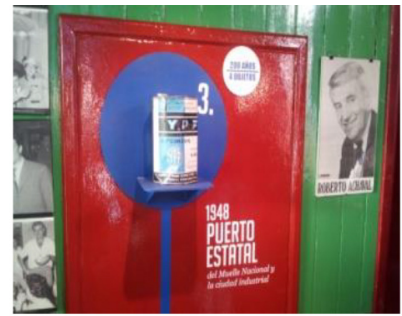

\section{Fortín Cuatreros / Av. Pernicci y Alvarado (Gral. Daniel Cerri)}

Muestra sobre el General Daniel Cerri, a 100 años de su fallecimiento, la creación del fortín Cuatreros y las relaciones interétnicas, también podrás ver imágenes y objetos del primer pueblo industrial del sudoeste bonaerense.

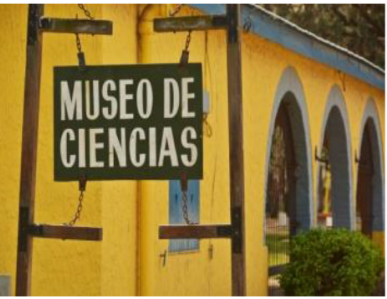

\section{Museo del Deporte / Drago 45}

Fundado el 8 de Octubre de 2011, es una institución municipal que alberga el patrimonio deportivo de la ciudad a lo largo de su rica historia intentando demostrar que los grandes fenómenos del deporte no son producto de la casualidad sino que responden a una historia, a un pasado que va logrando una evolución. Se pone exhiben las diferentes disciplinas del deporte bahiense y se fomenta la realización de eventos deportivos, competitivos y recreativos.

\section{Museo de La Aviación Naval Argentina / Base Aeronaval Cte. Espora}

Si te gusta la aviación este es el lugar indicado. Aquí, podrás conocer desde los primeros aviones que se utilizaron en la Armada Argentina hasta la indumentaria que utilizaban los pilotos. Un espacio que refleja la historia de las alas de la Armada Argentina.
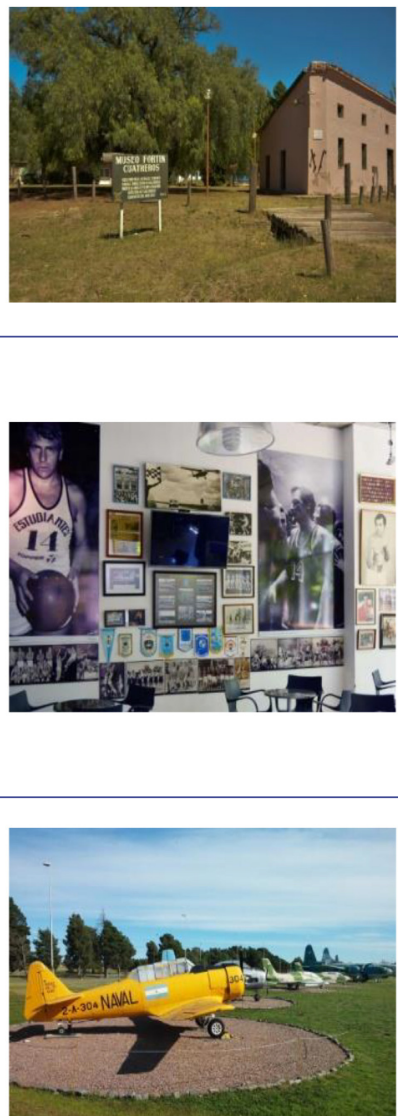


\section{Museo y Parque Estereoscópico El Histórico / Italia 19}

Un fascinante paseo por miles de objetos antiguos de todo tipo desde la época de la fundación de la ciudad hasta los de uso en la vida cotidiana, que suma valor educativo y entretenimiento muy valioso para niños, adolescentes y adultos. Además, podrán ver la Máquina del Tiempo y viajar al pasado en el Parque Estereoscópico del 1900, que es maravilla única en Sud-América y también podrán ver videos propios del museo que muestran a la antigua Bahía Blanca.

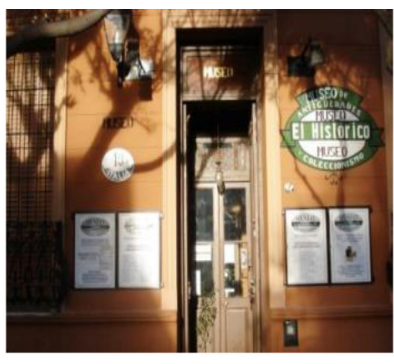

Museo de Ciencia y Técnica / Zelarrayán 2528

Es un espacio dinámico, donde podrás realizar un recorrido que te llevará a descubrir y aprender las ciencias, a través de módulos interactivos, en forma sencilla y divertida.

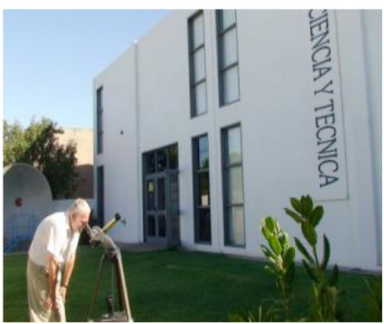

\section{Museo Ezequiel Martínez Estrada / Avenida Alem 908}

Ezequiel Martínez Estrada fue uno de los grandes ensayistas, escritores y poetas de Argentina, con reconocimiento internacional. Su Museo tiene abierta sus puertas todos los domingos de 15 a 18 horas en la Casa que fuera del escritor. Se realizan visitas guiadas orientando al visitante sobre la vida, obra e historia de este escritor y de su esposa, la artista plástica Agustina Morriconi.

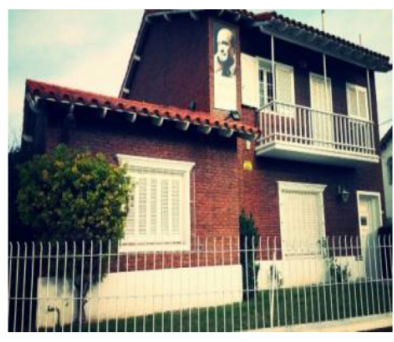

Camino Rural

En sus calles se observan edificaciones con un amplio valor históricoarquitectónico, conformando lugares de memoria cargados de anécdotas y sentimientos. En pleno siglo XXI aún hay localidades que viven en un

\section{Estación Cabildo (1903) / Zapiola 10}

Con su fundación quedó habilitada la nueva línea ferroviaria a Coronel Pringles, entre Plaza Constitución y Bahía Blanca. Su nombre es en homenaje al Cabildo Abierto de 1810. Fue una de las primeras construcciones que dieron origen al pueblo y a lo largo de su historia la comunidad siempre le ha asignado un importante valor simbólico.

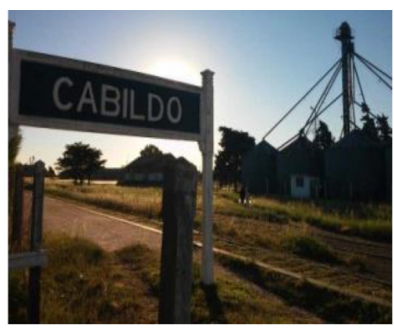

\section{Ex Hotel Italia (1912) y Ex Hotel Recreo (1921)/ Buenos Aires y Vicente López}

Ambos edificios alojaban a los viajeros que estaban de paso y a los trabajadores que llegaban para sumar manos al trabajo del tendido férreo. En estos edificios de proyectaban películas y funcionaban como importantes espacios de encuentro social. 


\section{Circuito}

ámbito sosegado, tranquilo y de mutuo conocimiento, donde la ubicación de un determinado punto se basa no en una altura de la calle sino en una persona de referencia, donde las bicicletas y auto pueden dejarse en la vereda sin preocuparse y donde los semáforos son elementos desconocidos. Cabildo, como la mayoría de los pueblos de la provincia de Buenos Aires, nació gracias al ferrocarril y la actividad agrícola. Estos lugares han sido seleccionados por la propia comunidad.

\section{Plaza de Mayo (1910) / Pringles y Saavedra}

En sus orígenes la plaza se encontraba alambrada como una suerte de potrero en donde las amas de casa solían colgar la ropa recién lavada. Hoy es el principal punto de encuentro de los adolescentes.

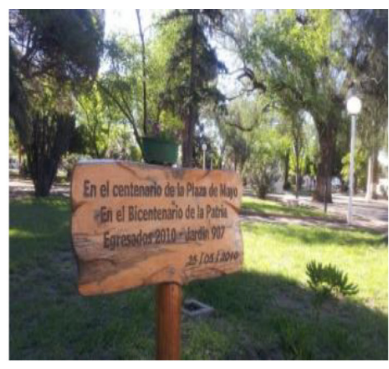

\section{Sociedad Italiana (1919) / Las Heras 36}

Fue fundada a instancias de don Feliciano Luchelli, jefe de la estación de ferrocarril en ese entonces, y de don José Lolli. En ella se agruparon familias que integraban la colectividad italiana. Junto a la colocación de la piedra fundacional se proyectó la obra de una sala teatral que sería construida con la cooperación de todos los italianos de la localidad.

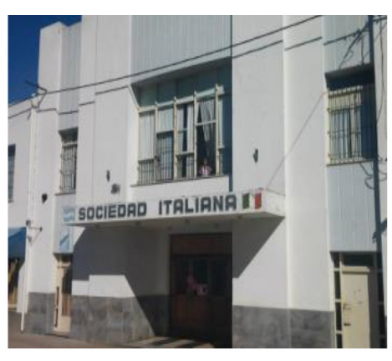

\section{Ex Correo / La Plata 58}

En 1903 se crea la Sociedad Española de Socorros Mutuos. En el año 1920 la Sociedad Española funda el edificio en el que funcionaría la oficina de correo postal.

\section{Prado Español / Alberti y San Martin}

En él se celebraban año a año las Romerías Españolas que consistían en un festejo de tres días que comenzaba con la llegada a la localidad de un grupo de músicos que venían en tren y que a partir del momento en que descendían de éste comenzaban a tocar piezas españolas con sus gaitas mientras se desplazaban por las calles del pueblo hasta llegar al Prado Español. Allí se hacían ferias de juegos, venta de bebidas, comidas y bailes.

\section{Cooperativa Sombra de Toro Ltda. (1948) y Planta de Acopio de Cereales}

36 productores de la zona rural fundaron una cooperativa para proveerse de insumos y comercializar sus productos. Esta cooperativa fue protagonista de la localidad durante más de 50 años llegando a contar con más de 500 socios. En 1965 se inauguró la Planta de Acopio de Cereales con elevadores de 6100 toneladas, barracas de mil metros cubiertos, balanza de alto pesaje y desvío ferroviario como muestra del momento de mayor apogeo del sector.

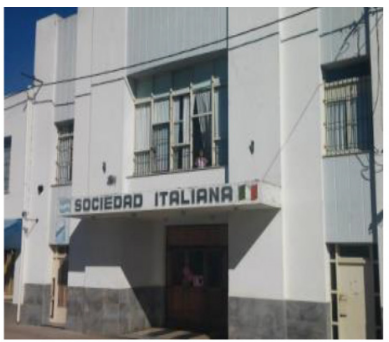

Julio - Diciembre 2018 | 157 


\section{Escuela No 19 "Remedios de Escalada de San Martin" (1907) / Ardohain 24}

Fue la primera escuela de la localidad cuando la mayoría de las manzanas eran potreros. Los alumnos de entonces recuerdan con emoción a la maestra Victoria Sinclair cuyo nombre lleva el barrio donde está el establecimiento, la plaza que se encuentra en frente a las instalaciones y el monumento que se encuentra en el centro de la misma.

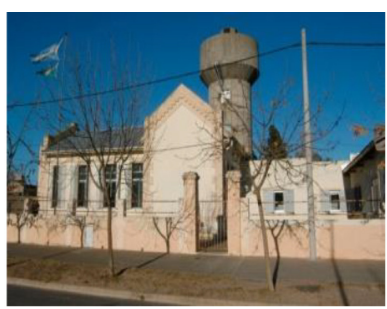

\section{Avda. Ardohain / Saenz Peña y Caronti}

Es un espacio fuertemente valorado por la comunidad local ya que allí los vecinos suelen caminar recorriendo sus más de dos mil metros rodeadas de arboledas que llevan a uno de los accesos al arroyo Sauce Grande.

\section{Cancha de Futbol "Club Atlético Pacifico" (1927) / Gregorio Garmendia 100}

El Club Pacífico de Cabildo nace de un grupo de niños fanáticos del Club Pacífico de Bahía Blanca luego de que este último saliera campeón invicto de la Liga del Sur. A partir de entonces forma un equipo que pronto comenzó a competir en la liga que se organizaba en la localidad e incluso en la Liga del Sur. Su equipo aún continúa compitiendo en la Liga del Sur y su cancha de fútbol reglamentaria es reconocida como una de las mejores de la zona.

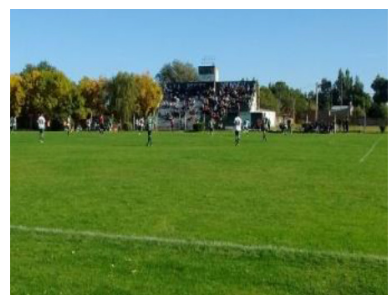

\section{Usina Eléctrica (1926) / San Martin y Saavedra}

Inicialmente se ubicaba en la esquina de Larrea y Vieytes, hoy es el cuartel de Bomberos. En el año 1956 se crea la Cooperativa de Luz y Fuerza que inicialmente brindaba el servicio de alumbrado de 19.00 a 2.00 hs. Los vecinos recuerdan que en la Romería Española la luz titilaba dos o tres veces como señal de que estaba por terminar la fiesta y todos volvían a sus casas antes de que se corte la luz. 


\section{CONCLUSIONES}

Las ciudades intermedias pueden desempeñar un papel importante en la organización y desarrollo de las actividades regionales y Bahía Blanca reúne condiciones para un buen desempeño, dado que tiene capacidad para atraer actividades competitivas, como lo son las turísticas.

Constituye un centro regional relevante en el sudoeste de la Provincia de Buenos Aires por sus actividades portuarias, industriales y de servicios, en especial en lo que respecta a la oferta educativa y de salud, de alta calidad y nivel de excelencia. En relación a su accesibilidad se encuentra bien posicionada y actualmente se desarrollan obras viales que facilitará una mejora en el transporte, sumado a los servicios aéreos que se están incorporando en la localidad tales como las líneas aéreas de bajo costo.

Si bien es cierto que la ciudad posee atractivos que pueden ser complementarios para acentuar el turismo de congresos y convenciones que año a año adquiere mayor relevancia en la localidad, muchas veces es sólo considerada como "ciudad de paso" hacia otros destinos. Sin embargo, podría considerarse la patrimonialización de recursos potenciales que puedan existir en la ciudad a fin de lograr un reconocimiento como destino turístico, tal podría ser el caso del termalismo. De esta manera, Bahía Blanca podría contar con una imagen de marca que la posicionaría de una manera diferente y destacada en el mercado turístico.

Las posibilidades para Bahía Blanca como ciudad intermedia tienen un gran potencial, y así lo afirma Santos (1996:155) "el mundo es solamente un conjunto de posibilidades, cuya efectividad depende de las oportunidades ofrecidas por los lugares".

\section{REFERENCIAS}

Antón Clavé, S. (2008). Turismo y ciudades. De la oportunidad del turismo urbano a los usos turísticos de las ciudades. En Destinos turísticos, viejos problemas, ¿nuevas soluciones? X Coloquio de Geografía del Turismo, Ocio y Recreación (AGE). Cuenca: ediciones de la Universidad de Castilla-La Mancha.

Barreto, M. (2009). Turismo urbano: Estrategias de planificación, en Comisión para la Preservación del Pa- trimonio Histórico Cultural de la Ciudad de Buenos Aires. Temas de patrimonio cultural, 2 (26), 196191.

Bellet Sanfeliu, C. y Llop Torné, J.M. (2004). Miradas a otros espacios urbanos: las ciudades intermedias. Scripta Nova Revista electrónica de geografía y ciencias sociales, 8 (165). Disponible en http:// www.ub.edu/geocrit/sn/sn-165.htm

Bertoncello, R., y luso, R. (2016). Turismo urbano en contexto metropolitano: Tigre como destino turístico en el Área Metropolitana de Buenos Aires (Argentina). Cuadernos de Geografía: Revista Colombiana de Geografía, 26 (2), 107-125.

Bolay, J. y RAbinovich, A. (2004). Ciudades intermedias: ¿una nueva oportunidad para un desarrollo regional coherente en América Latina. En Globalización e Intermediación Urbana en América Latina. Santo Domingo: FLACSO.

Espon. (2006). The Role of Small and Medium-Sized Towns. Final Report. Recuperado de http://www. espon.eu/main/Menu_Projects/Menu_ESPON2006Projects/Menu_StudiesScientificSupportProjects/

Instituto Nacional de Estadísticas y Censos. (2010). Censo Nacional de Población, Hogares y Viviendas Recuperado de http://www.indec.gob.ar/ftp/censos/2010/CuadrosDefinitivos/P2-D_6_56.pdf

Judd, D. y Fainstein, S. (1999). The Tourist City. London: Yale University Press.

Kotler, P. (1997). Mercadotecnia para hostelería y turismo. México, Prentice Hall.

Llop, J. M. (2008). Ciudades intermedias, entre sus territorios y la globalización. Modulor, (5), 9-13.

Marchena Gómez, M. (1995). El turismo metropolitano: una aproximación conceptual, en Estudios turísticos, (126), 7-21.

Méndez, R. (2006). Del distrito industrial al desarrollo territorial: estrategias de innovación en ciudades intermedias. IX Seminario. Internacional de la Red Iberoamericana de Investigadores sobre Globalización y Territorio. Universidad Nacional del Sur, Bahía Blanca.

Municipalidad de Bahía Blanca (2014). Mapa de accesibilidad vial. Recuperado de http://www.gifex.com/ 
argentina_maps/Bahia_Blanca_Access_Map_ Buenos_Aires_Prov_Argentina_2.htm

Municipalidad de Bahía Blanca (2017). Información sobre turismo en Bahía Blanca. Recuperado de http://www.bahia.gob.ar/conoce/

Municipalidad de Bahía Blanca (2017). Información sobre infraestructura física y de servicios en Bahía Blanca. Recuperado de http://www.bahia.gob.ar/ciudad

Page, S. (1995). Urban Tourism. New York: Routledge.

Pinassi, C. A. y Ercolani, P. (2012). El turismo urbano-metropolitano y su configuración espacial en las ciudades. Análisis de la focalidad urbana en bahía blanca (argentina). Revista TURyDES, 5 (13).

Prieto, M. B.; Schroeder, R. y Formiga, N. (2011). Ciudades intermedias: dinámica y perspectivas: el caso de Bahía Blanca - Argentina. Revista Geográfica de América Central (2), 1-17. Recuperado de http:// www.redalyc.org/pdf/4517/451744820424.pdf

Pulido, N. (2004). Globalización y surgimiento de "ciudades intermedias" en América Latina y Venezuela. Revista Geográfica Venezolana, 45(1), 91-121. Recuperado de http://www.saber.ula.ve/bitstream/123456789/24611/2/articulo45-1-4.pdf

Ramborger, M. A. y Lorda, M. A. (2010). Análisis de las transformaciones antrópicas de la franja costera de la Bahía Blanca a partir de la interpretación de fotografías aéreas. Revista Universitaria de geografía, 19 (1), 49-70. Recuperado de http://bibliotecadi- gital.uns.edu.ar/scielo.php?script=sci arttext\&pi$d=S 1852-42652010001100006 \&$ Ing=es\&nrm=iso

Rodríguez Vaquero, J. E. (2009). Turismo urbano y sistema territorial. Almería, modelo emergente. Nimbus, (23-24), 171-181.

Rodríguez Vignoli, J. (2002). Distribución territorial de la población de América Latina y el Caribe: tendencias, interpretaciones y desafíos para las políticas públicas. Serie Población y desarrollo, (32).

Santos, M. (1996). El espacio banal, una epistemología de la existencia. Discurso en Solemne Investidura de Doctor Honoris Causa; Universitat de Barcelona.

Schroeder, R. (2011). La actividad turístico-recreativa en la reestructuración del espacio urbano. El caso de una ciudad media: Bahía Blanca, Argentina. Revista Turismo y Sociedad, 12, 215-234. Recuperado de http://revistas.uexternado.edu.co/index.php/tursoc/article/view/3125/3507

Selby, M. (2004). Consuming the City: Conceptualizing and Researching Urban Tourist Knowledge. Tourism Geographies, 6 (2), 186-207.

Vera Rebollo, J. F. (coord.), López Palomeque, F., Marchena Gómez, M. y Antón, S. (1997). Análisis territoriales del turismo. Una nueva Geografía del Turismo. Barcelona, España: Ariel.

Vera Rebollo, F. (Coord.) et al. (2011). Análisis territorial del turismo y planificación de destinos turísticos. Valencia España: Tirant lo Blanch. 